\title{
Option pricing and replication with transaction costs and dividends
}

Stylianos PERRAKIS

University of Ottawa

J ean LEFOLL

University of Geneva

Research Paper $\mathbf{N}^{\circ} 8$ 


\title{
Option pricing and replication with transaction costs and dividends
}

\author{
Stylianos Perrakis ${ }^{\mathrm{a}}$ and Jean Lefoll ${ }^{* \mathrm{~b}}$ \\ ${ }^{a}$ Faculty of Administration and department of economics, University of Ottawa, \\ Ottawa, CANADA, KIN6N5 \\ ${ }^{\mathrm{b}}$ HEC and International Finance Laboratory, University of Geneva, \\ 1211 Genève 4, SWITZERLAND
}

\begin{abstract}
This paper derives optimal perfect hedging portfolios in the presence of transaction costs within the binomial model of stock returns, for a market maker that establishes bid and ask prices for American call options on stocks paying dividends prior to expiration. It is shown that, while the option holder's optimal exercise policy at the ex-dividend date varies according to the stock price, there are intervals of values for such a price where the optimal policy would depend on the holder's preferences. Nonetheless, the perfect hedging assumption still allows the derivation of optimal hedging portfolios for both long and short positions of a market maker on the option.
\end{abstract}

Keywords: Pricing; Transaction costs; American options; Dividends JEL classification: G13

This version July 1999

Forthcoming in the Journal of Economic Dynamics and Control

* Corresponding author: lefoll@hec.unige.ch.

Parts of the work were done while Lefoll was in sabbatical leave at the University of Ottawa during 1994-95 and while Perrakis was a Visiting Professor at ALBA, Greece, during 1997-98. The authors wish to thank the Canadian Social Sciences and Humanities Research Council and the Swiss Fonds National de la Recherche Scientifique for financial support under grant \#1214-040687.94, and Thierry Vessereau for research assistance. A preliminary version was presented at the AFFI meetings, Tunis, June 1994, and at the NFA meetings, September 1994. We wish to thank participants at doctoral seminars at Concordia University and Université de Montréal, for helpful advice and comments. We also acknowledge the helpful comments from three referees and from Michaël Selby guest editor of this issue. 


\section{EXECUTIVE SUMMARY}

In a market where market makers must quote bid and ask prices, like the SOFFEX, it is important to be able to determine the bid and ask prices of the traded assets. This is also true for negociated option contracts when the bid and ask prices must take transaction costs into account. The methodology developed in this paper allows us to derive bid and ask prices for American options on dividend-paying stocks under the assumption that the market makers hedge themselves perfectly against all possible investor decisions. Since the derived prices are independent from the market makers' preferences, including their taste for risk, the perfect hedging assumption increases the theoretical bid/ask spread. In fact, all possible spreads that may depend on market makers' risk aversion must lie within the perfectly hedged bid/ask spread.

In an empirical study using daily data on the SOFFEX we found that the average observed bid/ask spreads were smaller than the theoretical spreads derived by the algorithms presented in this article when there are dividends prior to option expiration, contrary to options on stocks without such dividends. From this it may be inferred that during the period under study the market makers did not necessarily try to hedge themselves perfectly. Nonetheless, the data show that the observed spreads were on average biased downwards and the quoted bid prices were lower than those corresponding to perfect hedging. Given that the theoretical prices assume that the underlying asset's price follows the binomial model, the bid/ask spread tends to increase with the number of times the market makers' portfolios are restructured. This increases the theoretical spread because of the transaction costs incurred in each restructuring. In order to counterbalance this effect, which is unavoidable in the binomial model under perfect hedging, we have adopted an ad hoc procedure of adjustment of the transaction costs. This assumes that these costs increase at a rate that decreases in proportion to the number of times the portfolios are restructured, as specified in this article. With this adjustment the average theoretical bid/ask spreads become comparable to those observed on the SOFFEX. Thus, with this ad hoc adjustment of the transaction costs and with the perfect hedging hypothesis it is possible to derive bid/ask spreads comparable to those observed on the SOFFEX, thus yielding bounds within which the market makers' spreads should lie whether or not they use perfect hedging.

The proposed algorithms allow a quick estimation of the theoretical bid and ask prices and may thus be used by market makers on the SOFFEX. They are, to our knowledge, the only ones that produce such prices under the perfect hedging hypothesis. The auhors have also extended their procedure to American put options and to options on stock indices. 


\section{Option Pricing and Replication with Transaction Costs and Dividends}

\section{Introduction}

This paper derives American call option prices and replicating portfolios under transaction costs when there are known dividends prior to option expiration. It thus extends similar derivations for European options originally introduced by Merton (1989), and subsequently extended by Boyle and Vorst (1992, BV), Bensaid et al (1992, BLPS), and Perrakis and Lefoll (1997a, PL).

The notion of option replication underlies the two main option pricing models in financial theory, the continuous-time Black and Scholes (1973) model, and the binomial model of Cox, Ross and Rubinstein (1979) and Rendleman and Bartter (1979). The European call option price is derived by constructing a portfolio that includes the stock and the riskless asset, whose return characteristics replicate exactly those of the option, under the assumption that there are no transaction costs. This assumption cannot be relaxed easily. Transactions costs manifest themselves on the side of the underlying stock by the existence not of a single price, but of an interval of prices contained within the bid and ask price of the stock. An option pricing model that incorporates transactions costs should derive the option bid and ask prices from the bid and ask prices of the underlying stock, as well as from other possible transactions costs.

This kind of derivation was first attempted by Merton (1989) for a binomial model that had only two periods till option expiration, by assuming that options are produced by financial intermediaries under perfect hedging. These intermediaries replicate the option with a stock-plusriskless asset portfolio that incorporates proportional transactions costs when changing the stock holdings; in this way they hedge their positions perfectly, namely they make sure that they have 
sufficient cash to cover their obligations under all circumstances. Two such portfolios are issued, for the option buyers and the option writers respectively, corresponding ultimately to the ask and bid prices of the option.

The Merton derivations were extended to any number of periods to expiration in the BV and BLPS studies. While the BV study used exact replication, BLPS pointed out that it may not be optimal to replicate the option to obtain perfect hedging: by not rebalancing the portfolio the intermediary avoids some transactions costs, ending up with more cash at expiration than required by perfect hedging. BLPS developed algorithms for optimal portfolio rebalancing in the presence of transactions costs when the option is at least perfectly hedged; such strategies are known as super-replication. They also derived conditions for the optimality of exact option replication. The PL study extended their approach to cases of non-convexity of the final constraints.

In this paper option prices and super-replicating portfolios ${ }^{1}$ are derived in a binomial model with transactions costs when there are known dividends to be paid to the stockholders at given times prior to the expiration of the option. The derived portfolios super-replicate investors' long and short positions in options under such conditions. It is well known since Merton (1973) that in such cases the European and American call options do not have the same price, and that the American option may be either prematurely exercised at the ex-dividend date, or left unexercised till expiration. Option prices with dividends in the absence of transactions costs were derived by Roll (1977), Geske (1979), and Whaley (1981), and extended by Selby and Hodges (1987), in the context of the Black-Scholes model. This paper bears the same relationship to the Merton, BV and BLPS studies as Roll, Geske, and Whaley to the Black-Scholes model. As with the earlier studies, its main contribution is the identification of the early exercise boundary, the stock prices at exdividend dates that separate early from deferred exercise. The introduction of transaction costs 
makes this boundary rather complex, insofar as there is now a region of such stock prices, rather than a single price, at each ex-dividend date: there is immediate (deferred) exercise above (below) this region, while within it the exercise depends on whether the last move was an up or a down.

Before closing this brief survey of the literature, we note some alternative approaches to option pricing with transactions costs. An early study by Leland (1985) derived an approximate option replication model under transaction costs within the continuous-time Black-Scholes model. Leland assumed an exogenously-given finite number of portfolio rebalancing periods, which did not constitute a perfectly-hedged position, with sufficient cash to cover all terminal option values. More recently Soner et al (1995) showed that the value of the portfolio replicating the long option in continuous time tends to the stock price for any finite transaction cost.

Other studies are based on optimizing portfolio choice (including options) for a given investor utility function. In contrast to perfect hedging, the resulting option reservation price would depend on the investor wealth and utility function used in the derivations. Examples of such an approach are Hodges and Neuberger (1989), Dumas and Luciano (1991), and Constantinides (1986). This approach has not been able till now to derive equilibrium option bid and ask prices. As Davis et al. (1993) point out, there are theoretical issues that remain unsolved, since the reservation prices for option buyers and writers define an empty set of equilibrium prices.

On the other hand, the main weakness of the perfectly-hedged binomial-based approaches to option pricing under transaction costs is the need to specify exogenously the number of steps in the binomial tree. This is a potentially fatal flaw, since the bid/ask spread increases with this number of steps. At the limit the ask price tends to the stock price, while the bid price is equal to the well-known Merton (1973) lower bound for finite values of binomial time steps ${ }^{2}$. 
A possible solution was proposed by Henrotte (1993) and Flesaker and Hughston (1994), who proposed replacing the fixed transaction cost parameter by one that declines in proportion to the square root of the number of binomial steps. This method is the only one so far that produces reasonable non-trivial option prices under transaction costs, both in continuous time and on binomial lattices. It serves as the main justification for the approach adopted in this paper, although the algorithms developed here do not depend on it. Further, several technical conditions necessary for our results are satisfied for reasonable parameter values under such an assumption.

In the next section we present the general model and review the results available for option pricing and replication in the binomial model in the presence of transactions costs and without any dividends. A single dividend is introduced in sections III and IV, for the long and short calls respectively, while section $\mathrm{V}$ extends the results to any number of dividends and presents some numerical examples. The proofs of the main results are given in summary form in the appendix. More detailed proofs of these results are available from our working paper (Perrakis and Lefoll, 1997b).

\section{The General Model}

Let $\mathrm{u}, \mathrm{d}$ and $\mathrm{R}$ denote the three parameters of the binomial process, denoting respectively the size of the up and down moves, and one plus the riskless rate of interest, with $d<R<u$. Let also $k$ denote the transactions cost parameter, assumed for simplicity the same for sales and purchases of stock. This implies that the purchase of $\$ 1$ of shares costs $\$(1+\mathrm{k})$, while the short sale of $\$ 1$ of shares yields $\$(1-\mathrm{k})$; we assume that there are no transactions costs in the riskless asset. The exercise price of the option is $\mathrm{X}$, and $\mathrm{T}$ is the expiration time of the option (in number of periods). At some time $\tau \in(0, T)$ there is a dividend $\mathrm{D}$ that is paid $^{3}$; this dividend can be constant in dollar or 
in yield terms, or any other function of the stock price at the ex-dividend date. Hence, if $S_{\tau}$ is the price of the stock at $\tau$ the subsequent values of the stock price follow the initial binomial process, with starting price ${ }^{4} S_{\tau} D$, assumed positive for all possible $S_{\tau}$. Let also $S_{0}$ denote the initial stock price. Our purpose is to derive the values of portfolios that super-replicate investors' long and short positions in the American option on such a stock; denoted by the subscripts a and b respectively. If the options are issued by a perfectly-hedged financial intermediary, as in Merton (1989), then their respective ask and bid prices are $\mathrm{C}_{\mathrm{ad}}\left(\mathrm{S}_{0}, \mathrm{~T}\right)$ and $\mathrm{C}_{\mathrm{bd}}\left(\mathrm{S}_{0}, \mathrm{~T}\right)$, with the subscript denoting the presence of a dividend.

Similarly, we denote by $\mathrm{C}_{\mathrm{a}}\left(\mathrm{S}_{0}, \mathrm{n}\right)$ and $\mathrm{C}_{\mathrm{b}}\left(\mathrm{S}_{0}, \mathrm{n}\right)$ the corresponding ask and bid prices when the initial stock price is $\mathrm{S}_{0}$, the expiration time is $\mathrm{n}$, and there are no dividends prior to expiration of the option. In other words, if $\mathrm{N}_{\mathrm{j}}$ and $\mathrm{B}_{\mathrm{j}}$ denote respectively the number of shares and amount of cash at time $\mathrm{j} \in[0, \mathrm{n}]$ in the super-replicating portfolios of long and short options, we have $\mathrm{C}_{\mathrm{a}}\left(\mathrm{S}_{0}, \mathrm{n}\right)=\mathrm{N}_{0 \mathrm{a}} \mathrm{S}_{0}+\mathrm{B}_{0 \mathrm{a}}, \mathrm{C}_{\mathrm{b}}\left(\mathrm{S}_{0}, \mathrm{n}\right)=-\left(\mathrm{N}_{0 \mathrm{~b}} \mathrm{~S}_{0}+\mathrm{B}_{0 \mathrm{~b}}\right)$, and the terminal portfolios $\left(\mathrm{N}_{\mathrm{n}}, \mathrm{B}_{\mathrm{n}}\right)$ are respectively equal to $(1,-\mathrm{X})$ and $(-1, \mathrm{X})$ for $\mathrm{C}_{\mathrm{a}}$ and $\mathrm{C}_{\mathrm{b}}$, or to $(0,0)$ in both cases, depending on the terminal value of $S_{n}$. The values $C_{a}$ and $C_{b}$ are in this case equal to those of the corresponding European options, and were derived in the previously-mentioned studies of Merton (1989), BV and BLPS.

In the BV study these derivations were by replication at every node of the binomial tree. However, their derivation for the short call is valid if and only if the following conditions hold ${ }^{5}$ :

$$
\mathrm{d}(1+\mathrm{k}) \leq \mathrm{R}(1-\mathrm{k})
$$

$\mathrm{R}(1+\mathrm{k}) \leq \mathrm{u}(1-\mathrm{k})$.

In the more general formulation of the BLPS study it was shown that replication is an optimal perfect hedging policy only for long call options with physical delivery of the asset, and for 
all European options when (1) holds. Otherwise, for short calls with physical delivery, and for both long and short calls with cash settlement, super-replication implies that it may be optimal not to rebalance the stock-plus-riskless asset portfolio at every node in order to save on transactions costs.

A key assumption of the BLPS study is that the optimal policy at option expiration be prespecified as a function of the terminal stock price $S_{n}$. This assumption was relaxed in PL, where it was shown that it is inconsistent with the perfect hedging requirement when there are transactions costs. For instance, for $S_{n} \in[X /(1+k), X /(1-k)]$ an option holder may or may not exercise the option, depending on his/her preference for holding stock or $\operatorname{cash}^{6}$ at time $\mathrm{n}$; perfect hedging implies that the intermediary must have enough cash to hedge either one of these two positions. In American options this dependence appears at every node of the binomial tree, thus requiring a major reformulation of the BLPS approach.

Relations (1) are important technical conditions on the binomial parameters, affecting the optimal hedging policies. In the PL study it was shown that BLPS algorithm may no longer be valid when (1) is violated, due to the presence of non-convexities in the final constraints in the program (4)-(5) below. When these constraints are non-convex the BLPS algorithm can identify only local minima of the objective function at every node of the binomial tree. For such cases PL derived an extension of the BLPS algorithm, that showed that the option bid price coincided with the well-known Merton lower bound for European calls, $\operatorname{Max}\left\{0, \mathrm{~S}_{0}-\mathrm{X} / \mathrm{R}^{\mathrm{n}}\right\}$, when the following inequality holds:

(2) $\mathrm{d}(1+\mathrm{k})>\mathrm{u}(1-\mathrm{k})$. 
In this paper it will be assumed that (1) holds, even though this is not necessary for all the derived results. The violations of (1) are discussed as an extension, and it is shown that when (2) holds the derived option bid and ask prices assume trivial values.

Let $\omega_{\mathrm{j}}$ denote a particular path from 0 to $\mathrm{j} \in[1, \mathrm{n}]$, i.e. a particular sequence of up and down moves, and $S_{j}\left(\omega_{j}\right)$ the corresponding stock price; clearly, $\omega_{j+1}=u \omega_{j}$ or $d \omega_{j}$. Following BLPS, we model the transactions costs by means of the function $\phi(y)$, which is equal to $(1+k) y$ for $y \geq 0$ and to $(1-\mathrm{k}) \mathrm{y}$ for $\mathrm{y} \leq 0$. Then for any time $\mathrm{j}$ the hedging portfolio must contain enough cash in the riskless asset to cover the subsequent position, including the transactions cost. This implies that:

(3) $R B_{j} \geq B_{j+1}+\phi\left(N_{j+1}-N_{j}\right) S_{j+1}\left(\omega_{j+1}\right)$,

where $\left(\mathrm{N}_{\mathrm{j}}, \mathrm{B}_{\mathrm{j}}\right)$ are dependent on the path $\omega_{\mathrm{j}}$. At expiration, for the long call with physical delivery the terminal portfolio $\left(N_{n}, B_{n}\right)$ is equal to $(1,-X)$ when $(1-k) S_{n} \geq X$ and to $(0,0)$ when $(1+k) S_{n} \leq X$, since all option holders will unequivocally exercise or let expire the option. For intermediate values of $S_{n}$, however, the option holders may or may not exercise the option, and the cash must be sufficient to hedge either action; this implies that $\operatorname{RB}_{\mathrm{n}-1} \geq \operatorname{Max}\left\{-\mathrm{X}+\phi\left(1-\mathrm{N}_{\mathrm{n}-1}\right) \mathrm{S}_{\mathrm{n}}\left(\omega_{\mathrm{n}}\right), \phi\left(-\mathrm{N}_{\mathrm{n}-1}\right) \mathrm{S}_{\mathrm{n}}\left(\omega_{\mathrm{n}}\right)\right\}$ for $S_{n} \in(X /(1+k), X /(1-k))$. The BLPS algorithm computes sequentially the optimal path-dependent portfolios by evaluating for each path the following function:

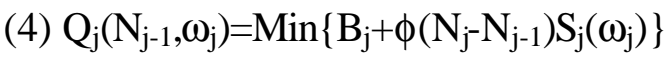

$$
\mathrm{N}_{\mathrm{j}}, \mathrm{B}_{\mathrm{j}}
$$

subject to

(5) $R B_{j} \geq \operatorname{Max}\left\{Q_{j+1}\left(N_{j}, u \omega_{j}\right), Q_{j+1}\left(N_{j}, d \omega_{j}\right)\right\}$. 
Finally, for $\mathrm{j}=0$ we have:

(6) $\mathrm{C}_{\mathrm{a}}\left(\mathrm{S}_{0}, \mathrm{n}\right)=\operatorname{Min}\left\{\mathrm{N}_{0 \mathrm{a}} \mathrm{S}_{0}+\mathrm{B}_{0 \mathrm{a}}\right\}$,

with respect to $\left(\mathrm{N}_{0 \mathrm{a}}, \mathrm{B}_{0 \mathrm{a}}\right)$, and subject to (5).

The function $\mathrm{Q}_{\mathrm{j}}$, which depends on the stock price and the stock $\mathrm{N}_{\mathrm{j}-1}$ inherited from the previous stage, represents the minimum cash necessary to rebalance the portfolio while maintaining a perfectly hedged position. The final stage of the problem, represented by (6), defines the option ask price as the minimum portfolio value that hedges perfectly the position of the option-issuing intermediary.

The derivation of the optimal bid price is similar to the ask in all steps except for the terminal conditions at option expiration. Here it is the intermediary that holds both the option and the hedging potfolio, which must be rebalanced optimally against short investors. Perfect hedging implies here that the intermediary must realize non-negative payoffs after liquidating both option and hedging portfolio. The intermediary's optimal action is clearly to exercise the option when (1-k) $S_{n} \geq X$, implying that $\left(N_{n}, B_{n}\right)=(-1, X)$; to let it expire when $S_{n}(1+k) \leq X$, yielding $\left(N_{n}, B_{n}\right)=(0,0)$; and to choose the optimal course of action depending on the inherited stock $\mathrm{N}_{\mathrm{n}-1}$ for $\mathrm{S}_{\mathrm{n}} \in(\mathrm{X} /(1+\mathrm{k}), \mathrm{X} /(1-\mathrm{k}))$, implying that $\mathrm{RB}_{\mathrm{n}-1}+\operatorname{Max}\left\{-\mathrm{X}-\phi\left(-1-\mathrm{N}_{\mathrm{n}-1}\right) \mathrm{S}_{\mathrm{n}}\left(\omega_{\mathrm{n}}\right),-\phi\left(-\mathrm{N}_{\mathrm{n}-1}\right) \mathrm{S}_{\mathrm{n}}\left(\omega_{\mathrm{n}}\right)\right\} \geq 0$. This last constraint is not necessarily convex, although when (1) holds convexity is preserved. The optimal bid price is the negative of the portfolio value solving the problem (3)-(6).

As shown in the BLPS Theorem 3, the program (3)-(6) has as a solution the replicating portfolio policy initially derived in the Merton-BV studies, for both long and short calls when (1) holds. A replicating portfolio policy replaces relations (4)-(5) of the BLPS super-replication program by a pair of equalities at every node of the binomial tree. Thus, the replicating portfolio 
$(\mathrm{N}, \mathrm{B})$ at any node $\mathrm{S}$ is found recursively from the portfolios $\left(\mathrm{N}_{\mathrm{i}}, \mathrm{B}_{\mathrm{i}}\right)$ of the successor nodes $\mathrm{S}_{\mathrm{i}}, \mathrm{i}=1,2$, with $\mathrm{S}_{1}=\mathrm{uS}, \mathrm{S}_{2}=\mathrm{dS}$, by means of relations (4)-(6) of BV, which are reproduced here:

$$
\begin{aligned}
& \mathrm{NSu}(1+\mathrm{k})+\mathrm{BR}=\mathrm{N}_{1} \mathrm{Su}(1+\mathrm{k})+\mathrm{B}_{1}, \\
& \mathrm{NSd}(1-\mathrm{k})+\mathrm{BR}=\mathrm{N}_{2} \mathrm{Sd}(1-\mathrm{k})+\mathrm{B}_{2},
\end{aligned}
$$

for the ask price, and

$$
\begin{aligned}
& \mathrm{NSu}(1-\mathrm{k})+\mathrm{BR}=\mathrm{N}_{1} \mathrm{Su}(1-\mathrm{k})+\mathrm{B}_{1}, \\
& \mathrm{NSd}(1+\mathrm{k})+\mathrm{BR}=\mathrm{N}_{2} \mathrm{Sd}(1+\mathrm{k})+\mathrm{B}_{2},
\end{aligned}
$$

for the bid price when (1) holds.

Before introducing the dividends we need some auxiliary results pertaining to the properties of $\mathrm{C}_{a}\left(\mathrm{~S}_{0}, \mathrm{n}\right)$ and $\mathrm{C}_{\mathrm{b}}\left(\mathrm{S}_{0} \cdot \mathrm{n}\right)$ as functions of the initial stock price $\underline{S}_{0}$. Indeed, if the option is not exercised at the ex-dividend date when the stock has value $S_{\tau}$, it will be hedged optimally by a portfolio with value equal to $C_{a}\left(S_{\tau}-D, T-\tau\right)$. This is a function defined on the sequence of points $S_{\tau}$ generated by the binomial tree at the ex-dividend date. After that date the properties of the unexercised option as a function of $S_{\tau}$ will determine the option holder's optimal policy at $\tau$, as it will be shown in the next section. Similar considerations apply also for the option's bid price.

The following auxiliary results are similar to well-known properties of European calls ${ }^{7}$, and will play a role when dividends are introduced.

Lemma 1. $\mathrm{C}_{\mathrm{a}}\left(\mathrm{S}_{0}, \mathrm{n}\right)$ is increasing and convex in $\mathrm{S}_{0}$, and $\partial \mathrm{C}_{\mathrm{a}} / \partial \mathrm{S}_{0} \leq 1$. Further, $\mathrm{N}_{0 \mathrm{a}}$ is non-decreasing and $B_{0 a}$ is non-increasing in $S_{0}$, with $\operatorname{Max}\left\{N_{0 a}\right\}=1$ and $\operatorname{Min}\left\{B_{0 a}\right\}=-X / R^{n}$ for $S_{0} d^{n} \geq X /(1-k)$. Proof. See appendix. 



while $-\mathrm{N}_{0 \mathrm{~b}}$ is non-decreasing and $-\mathrm{B}_{0 \mathrm{~b}}$ is non-increasing in $\mathrm{S}_{0}$, with $\operatorname{Max}\left\{-\mathrm{N}_{0 \mathrm{~b}}\right\}=1$ and $\operatorname{Min}\left\{-B_{o b}\right\}=X / R^{n}$. Further, in all cases $C_{b}\left(S_{0}, n\right) \leq C_{a}\left(S_{0}, n\right)$.

Proof. See appendix.

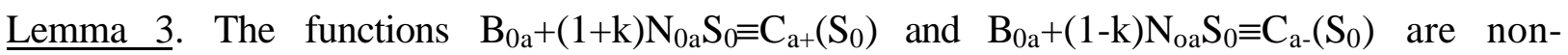
negative, non-decreasing and convex in $\mathrm{S}_{0}$. The same properties also hold for the functions $\left[-B_{0 b}-(1+k) N_{0 b} S_{0}\right] \equiv C_{b+}\left(S_{0}\right)$ and $\left[-B_{0 b}-(1-k) N_{o b} S_{0}\right] \equiv C_{b-}\left(S_{0}\right)$, but only when (1) is true.

Proof. See appendix.

These three lemmas establish very useful properties for the results to be derived in the next section. In particular, any initial stock price and time to option expiration in a binomial model define automatically a pair of portfolios, one of which replicates the long option, and the other hedges perfectly and optimally the short option. Both portfolios can be assumed known in any given case; they will be used in finding the option bid and ask values when a dividend exists prior to expiration.

\section{Ask Prices for American Calls with Transactions Costs and a Single Dividend}

Let $\mathrm{S}_{\tau} \in\left[\mathrm{S}_{0} \mathrm{~d}^{\tau}, \mathrm{S}_{0} \mathrm{u}^{\tau}\right]$ denote the stock price at the ex-dividend date. If the option is exercised the option holder (which can be the intermediary or an investor) receives a portfolio $(1,-\mathrm{X})$. Otherwise, the stock price model becomes binomial with initial price $S_{\tau}-\mathrm{D}$, and the option's expiration time is T- $\tau$. This last option has no dividends till expiration; hence, it is equivalent to an option on a binomial stock with starting price $S_{\tau}-\mathrm{D}$, that delivers the portfolio $(1,-\mathrm{X})$ in $\mathrm{T}-\tau$ periods. As discussed in the previous section, if this option is held by an investor then it can be hedged 
perfectly at $\tau$ by the intermediary by a portfolio $\left(\mathrm{N}_{\tau \mathrm{a}}, \mathrm{B}_{\tau \mathrm{a}}\right)$ that replicates exactly the call, and whose value is $\mathrm{N}_{\tau \mathrm{a}}\left(\mathrm{S}_{\tau} \mathrm{D}\right)+\mathrm{B}_{\tau \mathrm{a}}=\mathrm{C}_{\mathrm{a}}\left(\mathrm{S}_{\tau}-\mathrm{D}, \mathrm{T}-\tau\right)$.

The intermediary, which sells the option at the ask price, must hedge its position against either action by the investor. Conversely, the intermediary holds a long position with respect to option writers; it is perfectly hedged if it adopts the best policy (from its point of view) in each case. We know from the previous section that, if it does not exercise at $\tau$, its optimal hedging portfolio is $\left(\mathrm{N}_{\tau b}, \mathrm{~B}_{\tau \mathrm{b}}\right)$, that may or may not replicate the option depending on the values of the parameters; in either case its value is $-\left[\mathrm{N}_{\tau b}\left(\mathrm{~S}_{\tau}-\mathrm{D}\right)+\mathrm{B}_{\tau \mathrm{b}}\right]=\mathrm{C}_{\mathrm{b}}\left(\mathrm{S}_{\tau}-\mathrm{D}, \mathrm{T}-\tau\right)$.

Consider first the intermediary's hedging policy for investors having a long position on the option. These investors would choose to exercise the option at $\tau$ or hold it till expiration, depending on which alternative is more profitable. Clearly, if $S_{\tau}(1-k)-X \geq C_{a}\left(S_{\tau}-D, T-\tau\right)$ it is unequivocally better to exercise. Similarly, if $S_{\tau}(1+k)-X \leq C_{b}\left(S_{\tau}-D, T-\tau\right)$ the holder is better-off not exercising (he can do better by selling the unexercised option and buying one share of the stock). In-between the optimal decision depends on the holder's preference between holding stock at $\tau$ or at T. For the intermediary to be perfectly hedged the cash available at time $\tau$ should be sufficient to hedge either position. The key issue is to define the ranges of values of $S_{\tau} \in\left[S_{0} d^{\tau}, S_{0} u^{\tau}\right]$ for which these actions are optimal.

By Lemma $1 C_{a}\left(S_{\tau}-D, T-\tau\right)$ becomes asymptotically equal to its lower bound, $S_{\tau}-D-X / R^{T-\tau}$ for sufficiently large $S_{\tau}$. Similarly, by lemma $2 C_{b}\left(S_{\tau}-D, T-\tau\right)$ is either exactly equal to that same expression when (2) holds, or becomes asymptotically equal to it for sufficiently large $S_{\tau}$ when (1) holds. Hence, $X /(1+k) \geq D+X / R^{T-\tau}$ is a necessary condition for $C_{b}\left(S_{\tau}-D, T-\tau\right)$ to be greater than or 
equal to $S_{\tau}(1+k)-X$ for all $S_{\tau}$, implying that the option holder would never exercise the call at $\tau$. For exercise at $\tau$ to be profitable for all investors for some $S_{\tau}$, on the other hand, we must have $\mathrm{X} /(1$ $\mathrm{k})<\mathrm{D}+\mathrm{X} / \mathrm{R}^{\mathrm{T}-\tau}$.

We shall assume that this last inequality holds, since all other cases are special cases of it. Then the regions of values of $S_{\tau}$ that delineate the appropriate optimal option exercise policies depend on the intersection of the convex function $C_{a}\left(S_{\tau}-D, T-\tau\right)$ with the line $S_{\tau}(1-k)-X$; this intersection can have 0,1 or 2 common points. If $S_{\tau}(1-k)-X$ intersects $S_{\tau}-D-X / R^{T-\tau}$ above the point where the latter becomes equal to $\mathrm{C}_{\mathrm{a}}\left(\mathrm{S}_{\tau}-\mathrm{D}, \mathrm{T}-\tau\right)$, as in Figure 1 , then there is only one such intersection point, denoted by $S_{\tau 2}$, while $S_{\tau 1}$ denotes the intersection of $S_{\tau}(1+k)-X$ and $C_{b}\left(S_{\tau}-D, T-\tau\right)$. There may also be two intersection points ${ }^{8}, S_{\tau 2}$ and $S_{\tau 3}$, or no intersection point, when the entire function $C_{a}\left(S_{\tau} D, T-\tau\right)$ lies above the line $S_{\tau}(1-k)-X$. We shall use the case depicted in Figure 1 as our base case (see note 8 ). The key issue is the location of the points $S_{\tau i}, i=1,2$, with respect to the interval $\left[\mathrm{S}_{0} \mathrm{~d}^{\tau}, \mathrm{S}_{0} \mathrm{u}^{\tau}\right]$.

Suppose that we are as in Figure 1. If both points are within that interval then immediate exercise is clearly profitable for all option holders for $S_{\tau} \geq S_{\tau 2}$. Similarly, all option holders would choose not to exercise for $S_{\tau} \leq S_{\tau 1}$. For $S_{\tau} \in\left(S_{\tau 1}, S_{\tau 2}\right)$, on the other hand, some investors may choose to exercise and others may not, and the intermediary must be hedged against either action. Accordingly, the intermediary's position at $\tau$ should be as follows:

deliver $\left(\mathrm{N}_{\tau}, \mathrm{B}_{\tau}\right)=(1,-\mathrm{X})$ for $\mathrm{S}_{\tau} \geq \mathrm{S}_{\tau 2}$;

hold $\left(N_{\tau}, B_{\tau}\right)=\left(N_{\tau a}, B_{\tau a}\right)$ for $S_{\tau} \leq S_{\tau 1}$, where $\left(N_{\tau a}, B_{\tau a}\right)$ represents the long option-replicating portfolio ${ }^{9}$, corresponding to a starting stock price of $\left(\mathrm{S}_{\tau}-\mathrm{D}\right)$ and a maturity of $\mathrm{T}-\tau$; have enough cash at $\tau$ to hedge either one of these two deliveries for $S_{\tau} \in\left(S_{\tau 1}, S_{\tau 2}\right)$. 
Figure 1

The two values $S_{\tau 2}$ and $S_{\tau 1}$ are, respectively, the lowest $S_{\tau}$ satisfying $S_{\tau}(1-k)-X \geq C_{a}\left(S_{\tau}-D, T-\tau\right)$, and the highest $S_{\tau}$ satisfying $S_{\tau}(1+k)-X \leq C_{b}\left(S_{\tau}-D, T-\tau\right)$. The existence of the points $S_{\tau i}, i=1,2$, within the interval of admissible values of $S_{\tau}$ will depend on the given values of $S_{0}, X, u, d, R, D, T$ and $\tau$. If any one of those points does not exist within the appropriate interval (as, for instance, when $C_{a}\left(S_{\tau^{-}}\right.$ $\mathrm{D}, \mathrm{T}-\tau)$ lies entirely above $\left.\mathrm{S}_{\tau}(1-\mathrm{k})-\mathrm{X}\right)$ then the intermediary's optimal policy would cover only some of the above actions.

We can now derive the ask price for the call with dividends, $\mathrm{C}_{\mathrm{ad}}\left(\mathrm{S}_{0}, \mathrm{~T}\right)$, which can be found after the situation prevailing at the ex-dividend date $\tau$ has been established. It is found from the following program:

(P1) $\mathrm{C}_{\mathrm{ad}}\left(\mathrm{S}_{0}, \mathrm{~T}\right)=\operatorname{Min}\left\{\mathrm{N}_{0} \mathrm{~S}_{0}+\mathrm{B}_{0}\right\}$, subject to $\mathrm{RB}_{\mathrm{j}-1}\left(\omega_{\mathrm{j}}\right)-\mathrm{B}_{\mathrm{j}}\left(\omega_{\mathrm{j}}\right) \geq \phi\left(\mathrm{N}_{\mathrm{j}}\left(\omega_{\mathrm{j}}\right)-\mathrm{N}_{\mathrm{j}-1}\left(\omega_{\mathrm{j}}\right)\right) \mathrm{S}_{\mathrm{j}}\left(\omega_{\mathrm{j}}\right)$ for every $\mathrm{j} \leq \tau-1$ and for every path $\omega_{j}$.

At $j=\tau$, and for the situation depicted in Figure 1, the above constraint is replaced by the following:

$$
\mathrm{RB}_{\tau-1} \geq-X+\phi\left(1-\mathrm{N}_{\tau-1}\right) \mathrm{S}_{\tau}\left(\omega_{\tau}\right), \mathrm{S}_{\tau}\left(\omega_{\tau}\right) \in\left\{\left[\mathrm{S}_{0} \mathrm{~d}^{\tau}, \mathrm{S}_{0} \mathrm{u}^{\tau}\right] \cap\left[\mathrm{S}_{\tau} ; \mathrm{S}_{\tau}\left(\omega_{\tau}\right)>\mathrm{S}_{\tau 2}\right]\right\}
$$

(8b) $\quad \mathrm{RB}_{\tau-1} \geq \mathrm{B}_{\tau \mathrm{a}}+\phi\left(\mathrm{N}_{\tau \mathrm{a}}-\mathrm{N}_{\tau-1}\right)\left[\mathrm{S}_{\tau}\left(\omega_{\tau}\right)-\mathrm{D}\right]-\mathrm{DN}_{\tau-1}, \mathrm{~S}_{\tau}\left(\omega_{\tau}\right) \in\left\{\left[\mathrm{S}_{0} \mathrm{~d}^{\tau}, \mathrm{S}_{0} \mathrm{u}^{\tau}\right] \cap\left[\mathrm{S}_{\tau} ; \mathrm{S}_{\tau}\left(\omega_{\tau}\right) \leq \mathrm{S}_{\tau 1}\right]\right\}$

(8c) $\quad \operatorname{RB}_{\tau-1} \geq \operatorname{Max}\left\{-X+\phi\left(1-\mathrm{N}_{\tau-1}\right) \mathrm{S}_{\tau}\left(\omega_{\tau}\right), \mathrm{B}_{\tau \mathrm{a}}+\phi\left(\mathrm{N}_{\tau \mathrm{a}}-\mathrm{N}_{\tau-1}\right)\left[\mathrm{S}_{\tau}\left(\omega_{\tau}\right)-\mathrm{D}\right]-\mathrm{DN}_{\tau-1}\right\}$ for $\mathrm{S}_{\tau}\left(\omega_{\tau}\right) \in\left\{\left[\mathrm{S}_{0} \mathrm{~d}^{\tau}, \mathrm{S}_{0} \mathrm{u}^{\tau}\right] \cap\left(\mathrm{S}_{\tau 1}, \mathrm{~S}_{\tau 2}\right)\right\}$.

We note that at $\tau-1$ the portfolio $\left(\mathrm{N}_{\tau-1}, \mathrm{~B}_{\tau-1}\right)$ that hedges the option is entitled to the dividend even if the option holder decides not to exercise, thus accounting for the extra cash $\mathrm{DN}_{\tau-1}$ in the RHS of $(8 \mathrm{a}, \mathrm{b}, \mathrm{c})$. Let $\mathrm{W}_{\mathrm{m}}\left(\mathrm{N}_{\tau-1}, \mathrm{~S}_{\tau}\right)$ denote the RHS of $(8 \mathrm{~m}), \mathrm{m}=\mathrm{a}, \mathrm{b}$. 
The program (P1) is an adaptation of the BLPS algorithm for the dividend case with a horizon at the x-dividend date $\tau$, with a few important differences. Thus, although there is still physical delivery of the option in some terminal states, the terminal portfolio $\left(\mathrm{N}_{\tau}, \mathrm{B}_{\tau}\right)$ is no longer prespecified. Nonetheless, the RHS of the constraints $(8 \mathrm{a}, \mathrm{b}, \mathrm{c})$ is convex in $\mathrm{N}_{\tau-1}$, since it is the maximum of two convex functions. Hence, by setting $\mathrm{Q}_{\tau}\left(\mathrm{N}_{\tau-1}, \omega_{\tau}\right) \equiv$ RHS of $(8 \mathrm{a}, \mathrm{b}, \mathrm{c})$, we note that $\mathrm{Q}_{\tau}$ is convex in $\mathrm{N}_{\tau-1}$, implying that Lemma 5 of BLPS is valid, and $\mathrm{Q}_{\mathrm{j}}\left(\mathrm{N}_{\mathrm{j}-1}, \omega_{\mathrm{j}}\right)$ as given by (4) is valid for all $j \leq \tau-1$.

Similarly, Theorem 1 of that same BLPS study continues to hold, since its proof is based solely on this convexity property and the definition of the program. This theorem says that for every path $\omega_{j}$ and for every $j \in[1, \tau-1]$ in the binomial tree there exist two values $N_{\min }$ and $N_{\max }$, $\mathrm{N}_{\min } \leq \mathrm{N}_{\max }$, such that $\mathrm{N}_{\mathrm{j}}{ }^{*}$, the optimal $\mathrm{N}_{\mathrm{j}}$ in the minimization program (4), is set equal to $\mathrm{N}_{\min }$ for $\mathrm{N}_{\mathrm{j}-1} \leq \mathrm{N}_{\min }$, to $\mathrm{N}_{\max }$ for $\mathrm{N}_{\mathrm{j}-1} \geq \mathrm{N}_{\max }$, and is left unchanged at $\mathrm{N}_{\mathrm{j}-1}$ for $\mathrm{N}_{\mathrm{j}-1} \in\left(\mathrm{N}_{\min }, \mathrm{N}_{\max }\right)$. This theorem provides an algorithm for the derivation of the optimal hedging portfolio. These values $\mathrm{N}_{\min }$ and $\mathrm{N}_{\max }$ at any time $\mathrm{j}$ are independent ${ }^{10}$ of $\mathrm{N}_{\mathrm{j}-1}$ and, hence, of the path $\omega_{\mathrm{j}}$. It follows, therefore, that the optimal policy at every node of the binomial tree is independent of $\omega_{j}$, even though the optimal $\mathrm{N}_{\mathrm{j}}$ clearly depends on $\mathrm{N}_{\mathrm{j}-1}$. Hence, it suffices to determine $\mathrm{N}_{\min }$ and $\mathrm{N}_{\max }$ at every node, by applying (4) and (5). Hereafter we drop the path $\omega_{\mathrm{j}}$ as an argument from all expressions.

Although the BLPS theory applies for the evaluation of the ask price with dividends, the computations will be considerably simplified if the range of possible portfolios can be narrowed at each node. The following result demonstrates that replication is the optimal policy for the long call under fairly general conditions ${ }^{11}$. 
Theorem 1. Assume that:

(9)

$$
\mathrm{R}(1+\mathrm{k})<\mathrm{u}(1+\mathrm{k})-\mathrm{kD} / \mathrm{S}_{\tau-1}
$$

$\mathrm{R}(1-\mathrm{k})>\mathrm{d}(1-\mathrm{k})+\mathrm{kD} / \mathrm{S}_{\tau-1}$

Then a unique option replicating portfolio in the presence of dividends exists and is the optimal perfectly-hedging policy for the long call if inequalities (9) hold.

Proof. See appendix.

The validity of this theorem depends on the technical conditions (9), since if these conditions do not hold in a strict form the optimal hedging policy is not necessarily unique. A direct comparison of (1) and (9) shows that (1) implies (9) if $2 S_{\tau-1} \geq D$, which obviously holds. On the other hand, for general parameter values (9) is not necessarily a weaker inequality than (2). Under the commonly used definition of $\mathrm{u}, \mathrm{d}$ and $\mathrm{R}$ shown in (12) below, however, it can be shown that (9) holds also under (2) for most reasonable values of $\mathrm{k}$ and the dividend rate. This is discussed further in section $\mathrm{V}$.

Thus, the replicating portfolio emerges as a solution to the optimal hedging problem for the asking price of an option in the presence of dividends when conditions (9) hold. The main difference with the no-dividend case in computing the option ask price $\mathrm{C}_{\mathrm{ad}}$ lies at the ex-dividend time, at which the perfectly-hedging intermediary must be prepared to restructure its hedging portfolio to face either delivery of the stock, or default to the optimal hedging portfolio after the dividend has been paid. The recursive relations needed to evaluate the replicating portfolio at time $\tau$-1 differ from those applicable to all time periods $j \in[0, \tau-2]$, where the optimal hedging portfolio is derived by applying relations (7a). By contrast, at $\tau-1$ the form of the equations determining the optimal portfolio $\left(\mathrm{N}_{\tau-1}{ }^{*}, \mathrm{~B}_{\tau-1}{ }^{*}\right)$ depends on the location of the successor nodes $\mathrm{S}_{\tau}$ with respect to the intervals defined in the RHS of $(8 \mathrm{a}, \mathrm{b}, \mathrm{c})$. For instance, for $\mathrm{uS}_{\tau-1} \leq \mathrm{S}_{\tau 1}$ the optimal portfolio at $\tau-1$ must 
replicate portfolios that, in turn, replicate the options expiring at $\mathrm{T}$ with starting stock prices $\mathrm{uS}_{\tau-1^{-}} \mathrm{D}$ and $d S_{\tau-1}$-D. Similarly, when both $u S_{\tau-1}$ and $d S_{\tau-1}$ lie above $S_{\tau 2}$, the optimal portfolio at $\tau-1$ replicates the portfolio $(1,-\mathrm{X})$. In this last case it is clear that (7a) still apply. In all other cases, though, these relations must be modified to take into account the existence of dividends.

When at least one of the successor nodes of $S_{\tau-1}$ lies within the interval $\left(S_{\tau 1}, S_{\tau 2}\right)$ the portfolio $\left(\mathrm{N}_{\tau-1} *, \mathrm{~B}_{\tau-1} *\right)$ replicates a position that may correspond to immediate or deferred exercises for both successor nodes, or to immediate exercise for an up move and deferred exercise for a down move. It can be shown that the constraints $\mathrm{W}_{\mathrm{b}}\left(\mathrm{N}_{\tau-1}, \mathrm{u} \mathrm{S}_{\tau-1}\right)$ and $\mathrm{W}_{\mathrm{b}}\left(\mathrm{N}_{\tau-1}, \mathrm{~d} \mathrm{~S}_{\tau-1}\right)$ intersect at a single value of $N_{\tau-1}$ that lies within the interval $\left[N_{\tau a}(d), N_{\tau a}(u)\right]$; the corresponding portfolio is given by the system:

(10a) $\mathrm{u}(1+\mathrm{k}) \mathrm{S}_{\tau-1} \mathrm{~N}_{\tau-1}+\mathrm{RB}_{\tau-1}-\mathrm{kDN}_{\tau-1}=(1+\mathrm{k}) \mathrm{N}_{\tau \mathrm{a}}(\mathrm{u})\left(\mathrm{uS}_{\tau-1}-\mathrm{D}\right)+\mathrm{B}_{\tau \mathrm{a}}(\mathrm{u})$

(10b) $\mathrm{d}(1-\mathrm{k}) \mathrm{S}_{\tau-1} \mathrm{~N}_{\tau-1}+\mathrm{RB}_{\tau-1}+\mathrm{kDN}_{\tau-1}=(1-\mathrm{k}) \mathrm{N}_{\tau \mathrm{a}}(\mathrm{d})\left(\mathrm{dS}_{\tau-1}-\mathrm{D}\right)+\mathrm{B}_{\tau \mathrm{a}}(\mathrm{d})$

with deferred exercise in both successor nodes, as in equation (8b). The only other possibility is when $\mathrm{W}_{\mathrm{a}}\left(\mathrm{N}_{\tau-1}, \mathrm{uS} \mathrm{S}_{\tau-1}\right)$ intersects with $\mathrm{W}_{\mathrm{b}}\left(\mathrm{N}_{\tau-1}, \mathrm{dS}_{\tau-1}\right)$ at a value $\mathrm{N}_{\tau-1}>\mathrm{N}_{\tau \mathrm{a}}(\mathrm{d})$. This intersection defines a portfolio replicating immediate and deferred exercise for up and down moves respectively, with corresponding stockholdings $\mathrm{N}_{\tau}=1$ and $\mathrm{N}_{\tau}=\mathrm{N}_{\tau \mathrm{a}}(\mathrm{d})$; it is given by the system:

(11a) $\mathrm{u}(1+\mathrm{k}) \mathrm{S}_{\tau-1} \mathrm{~N}_{\tau-1}+\mathrm{RB}_{\tau-1}=\mathrm{u}(1+\mathrm{k}) \mathrm{S}_{\tau-1}-\mathrm{X}$

(11b) (same as (10b)). 
It can be easily seen that when at least one of $\mathrm{uS}_{\tau-1}$ or $\mathrm{dS}_{\tau-1}$ lies within the interval $\left(\mathrm{S}_{\tau 1}, \mathrm{~S}_{\tau 2}\right)$ the optimal replicating portfolio $\left(\mathrm{N}_{\tau-1}{ }^{*}, \mathrm{~B}_{\tau-1} *\right)$ is the one corresponding to the largest $\mathrm{N}_{\tau-1}$ solving $(10 a, b)$ or $(11 a, b)$. Further, it can be shown that if $(11 a, b)$ is the appropriate system for some value of $S_{\tau-1}$ then $(10 a, b)$ cannot be the appropriate system for any higher values of $S_{\tau-1}$.

Hence, the early exercise boundary, which is a single value of the stock price in the absence of transaction costs, is now replaced by the set of values $\left(S_{\tau 1}, S_{\tau 2}\right)$ of the stock price at time $\tau$, which define the regions $\left\{S_{\tau}: S_{\tau} \leq S_{\tau 1}\right\},\left\{S_{\tau}: S_{\tau} \geq S_{\tau 2}\right\},\left\{S_{\tau}: S_{\tau} \in\left(S_{\tau 1}, S_{\tau 2}\right)\right\}$. These can be easily translated to corresponding intervals of values of $S_{\tau-1}$. For $S_{\tau-1} \in\left(S_{\tau 1} / u, S_{\tau 2} / d\right)$ there exists a (possibly empty) subinterval $\left[S_{\tau-1,1}, S_{\tau-1,2}\right] \subset\left(S_{\tau 1} / u, S_{\tau 2} / d\right)$ of values of $S_{\tau-1}$, such that $\left(N_{\tau-1}{ }^{*}, B_{\tau-1}{ }^{*}\right)=(1,-X)$ for $S_{\tau-1} \geq S_{\tau-1,2}$, $\left(\mathrm{N}_{\tau-1} *, \mathrm{~B}_{\tau-1}{ }^{*}\right)$ is the solution of $(10 \mathrm{a}, \mathrm{b})$ for $\mathrm{S}_{\tau-1} \leq \mathrm{S}_{\tau-1,1}$, and $\left(\mathrm{N}_{\tau-1}{ }^{*}, \mathrm{~B}_{\tau-1} *\right)$ is the solution of $(11 \mathrm{a}, \mathrm{b})$ for $\mathrm{S}_{\tau-1} \in\left(\mathrm{S}_{\tau-1,1}, \mathrm{~S}_{\tau-1,2}\right)$. Once $\left(\mathrm{N}_{\tau-1}{ }^{*}, \mathrm{~B}_{\tau-1} *\right)$ have been defined at every node, we find $\left(\mathrm{N}_{\mathrm{j}}{ }^{*}, \mathrm{~B}_{\mathrm{j}}{ }^{*}\right)$ for $\mathrm{j} \in[0, \tau-2]$ by applying (7a).

Example. Let $\mathrm{S}_{0}=\mathrm{X}=100, \mathrm{R}=1, \mathrm{~T}=3, \mathrm{u}=1.05, \mathrm{~d}=1 / \mathrm{u}, \mathrm{D}=5, \tau=2, \mathrm{k}=6 \%$. The corresponding binomial tree is shown in Figure 2, together with the three values of $C_{a}\left(S_{\tau}-D, 1\right)$ at $\tau$, at the nodes labelled 1,2,3; the bid prices at $\tau$ for the unexercised calls are given by the Merton bound $\operatorname{Max}\left\{0, S_{\tau^{-}} \mathrm{D}-\mathrm{X} / \mathrm{R}\right\}$, which is 0 at nodes 2 and 3 and equal to 5.25 at node 1 . The values $\mathrm{C}_{\mathrm{ai}}\left(\mathrm{S}_{\tau^{-}}\right.$ $\mathrm{D}, 1$ ), $\mathrm{i}=1,2$, are found by applying the system (7a) with $\mathrm{N}_{1}=1, \mathrm{~B}_{1}=-\mathrm{X} / \mathrm{R}, \mathrm{N}_{2}=\mathrm{B}_{2}=0$, to the corresponding nodes; for instance, for $\mathrm{S}=105.25$ the solution of ( $7 \mathrm{a})$ yields $\mathrm{N}=0.748, \mathrm{~B}=-70.477$. With these values it is clear that at $\tau$ we have $C_{a}\left(S_{\tau}-D, T-\tau\right)>S_{\tau}(1-k)-X$ at nodes 1 and 2 , while $S_{\tau 1}$ coincides with node 3 in Figure 2 . Hence, in both nodes 1 and 2 the intermediary may face either immediate or deferred exercise, and we need to determine by applying (8c) which one of the two will impose the heaviest cash requirements. At node $1 \mathrm{~W}_{\mathrm{a}}\left(\mathrm{N}_{\tau-1}, \mathrm{~S}_{1}\right)=-100+110.25$ 
$\left(1-\mathrm{N}_{\tau-1}\right) 1.06>\mathrm{W}_{\mathrm{b}}\left(\mathrm{N}_{\tau-1}, \mathrm{~S}_{1}\right)=-70.477-5 \mathrm{~N}_{\tau-1}+105.25 \phi\left(0.748-\mathrm{N}_{\tau-1}\right)$ for all $\mathrm{N}_{\tau-1} \in[0,1]$, while at point $2 \mathrm{~W}_{\mathrm{a}}\left(0, \mathrm{~S}_{2}\right)>\mathrm{W}_{\mathrm{b}}\left(0, \mathrm{~S}_{2}\right)$ but $\mathrm{W}_{\mathrm{a}}\left(1, \mathrm{~S}_{2}\right)<\mathrm{W}_{\mathrm{b}}\left(1, \mathrm{~S}_{2}\right)$. At node 1 , therefore, the intermediary should hedge against immediate exercise, at node 3 against deferred exercise, and at node 2 against both immediate and deferred exercise depending on $\mathrm{N}_{\tau-1}$. Hence, at $\tau-1$ the hedging portfolios for the two paths originating from each one of the nodes A and B are found by solving system $(11 \mathrm{a}, \mathrm{b})$ at both nodes, yielding $\mathrm{N}_{\mathrm{A}}{ }^{*}=0.6952, \mathrm{~B}_{\mathrm{A}}^{*}=-64.384, \mathrm{~N}_{\mathrm{B}}{ }^{*}=0.2154, \mathrm{~B}_{\mathrm{B}} *=-18.426$. Last, at the origin we get by applying ( $7 \mathrm{a}$ ) that $\mathrm{N}_{0}=0.5574, \mathrm{~B}_{0}=-46.092$, yielding $\mathrm{C}_{\mathrm{ad}}=9.652$.

Figure 2

Next we examine the limiting form of the call ask price when the number of periods to the ex-dividend date becomes very large. Here it will be ultimately assumed ${ }^{12}$ that the dividend is a constant proportion $\gamma$ of $S_{\tau}$, where $\gamma$ satisfies (9). The limiting process of the binomial model is as in Cox, Ross and Rubinstein (1979), with u, d and R given by

(12) $u=e^{\sigma \sqrt{ } h}, d=1 / u, R=e^{r h}$,

where $\mathrm{h} \equiv \mathrm{t} / \tau=\left(\mathrm{t}_{1}-\mathrm{t}\right) /(\mathrm{T}-\tau), \mathrm{t}$ and $\mathrm{t}_{1}$ are the continuous times to ex-dividend date and option expiration respectively, $\tau$ and $\mathrm{T}$ are the numbers of discrete periods within $t$ and $t_{1}, \sigma$ is the volatility of the stock, and $\mathrm{r}$ is the riskless rate of interest.

As in BV pp. 274-276, the evaluation of the replicating portfolio corresponds to a discounted expectation under a modified Markovian process, in which the transition probabilities depend on the previous move. The Markovian process consists of a sequence of random variables $\mathrm{x}_{1}, \ldots, \mathrm{x}_{\tau}$, each one of which can have only two states with values $\ln u$ and $\operatorname{lnd}$. The stock price $\mathrm{S}_{\tau}$ is 
equal to $\mathrm{S}_{0} \mathrm{e}^{\mathrm{Y}}$, where $\mathrm{Y}=\Sigma \mathrm{x}_{\mathrm{j}}$. In the appendix it is shown that $\mathrm{C}_{\mathrm{ad}}$ may be approximated by the following expression, with the expectation taken with respect to the random variable Y:

(13) $C_{a d}=R^{-\tau} E\left\{\operatorname{Max}\left[S_{0} e^{Y}-X, B_{\tau a}+N_{\tau a}(1-\gamma) S_{0} e^{Y}\right]\right\}$.

For $\mathrm{k}=0$ expression (13) becomes the value of an American call option with a single proportional dividend payable at $\tau$ under the binomial model. It is well-known ${ }^{13}$ that no closedform solution exists for the limiting form of the value of such a call option when $\tau \rightarrow \infty$. American calls with dividends are generally evaluated by the Roll-Geske-Whaley (RGW) procedure, which takes the discounted risk-neutral expectation of the maximum of the immediate and deferred exercise values of the option at the ex-dividend date, under the lognormal distribution that forms the limit $^{14}$ of the binomial process (12). (13), therefore, does not converge to a closed-form expression. It can be shown, on the other hand, that for a large $\tau$ an approximate limiting lognormal distribution of the stock price $S_{\tau}$ exists under our process, similar to the limiting distribution of (12) but incorporating the transactions costs. The limiting form of $\mathrm{C}_{\mathrm{ad}}$ is then expressed by the following result.

Theorem 2. For large $\tau$ and $\mathrm{T}-\tau$ and small $\mathrm{k}$ the ask price $\mathrm{C}_{\mathrm{ad}}$ of a call option issued by a perfectlyhedged intermediary when there is a constant dividend yield $\gamma$ policy at $\mathrm{t}$ can be approximated by a modified $^{15}$ RGW procedure, ie. by $\mathrm{e}^{-\mathrm{rt}}$ times the expectation of the function $\operatorname{Max}\left\{S_{t}-X, C_{a}\left((1-\gamma) S_{t}, t_{1}-t\right)\right\}$, the latter evaluated with a risk-neutral lognormal distribution with variance $\sigma^{2}[1+(2 \mathrm{k} V \tau) /(\sigma \sqrt{ } \mathrm{t})]$. This approximation has the same relationship to the discrete process used in (13) as the original RGW approach has to the binomial American call option value.

Proof. See appendix. 
Theorem 2 provides an easy way of extending the RGW procedure in order to approximate the call ask price in the presence of dividends. Of particular interest are approximations incorporating the Henrotte-Flesaker and Hughston assumption that the transaction cost parameter varies inversely with the number of binomial periods to ex-dividend date or to option expiration. In our notation this means that $\mathrm{k}=\mathrm{K} V \mathrm{~h}$, where $\kappa$ is a constant parameter, implying that the variance of the limiting lognormal process is $\sigma^{2}(1+2 \kappa / \sigma)$. Examples of the accuracy of the approximation for various values of $\mathrm{t}, \mathrm{k}$ and/or $\kappa$ are given in Section $\mathrm{V}$.

\section{Bid Prices for American Calls With a Single Dividend}

The optimal perfect hedging policy is somewhat different for the short call with dividends. Here it is the intermediary that has the choice of exercising the option at $\tau$ or holding it till expiration. Nonetheless, the stock price limits $S_{\tau i}, i=1,2,3$ are still valid in terms of the optimality of the exercise policy. At the ex-dividend time $\tau$ the intermediary finds itself holding a call option plus the hedging portfolio. It can exercise the option or hold it till expiration, in which case it must also restructure the portfolio, so that it guarantees non-negative payoffs at $\mathrm{T}$. The optimal hedging portfolio at $\tau$ is the one that corresponds to the best policy, of exercising or restructuring and waiting till $\mathrm{T}$.

As in the no-dividend case, we treat separately the two cases where either (1) or (2) hold. If (1) hold then the optimal hedging portfolio at $\tau$, if the option is not exercised, is independent of the holdings $\left(\mathrm{N}_{\tau-1}, \mathrm{~B}_{\tau-1}\right)$, and is equal to the portfolio $\left(\mathrm{N}_{\tau \mathrm{b}}, \mathrm{B}_{\tau \mathrm{b}}\right)$. This is the optimal hedging portfolio for a short option without dividends, expiring T- $\tau$ periods later with exercise price $\mathrm{X}$ and starting stock 
price $S_{\tau}$-D. By contrast, the optimal hedging policy for such an option when (2) holds is dependent on the holdings $\left(\mathrm{N}_{\tau-1}, \mathrm{~B}_{\tau-1}\right)$.

In all cases the bid price $\mathrm{C}_{\mathrm{bd}}\left(\mathrm{S}_{0}, \mathrm{~T}\right)$ of a call option on a stock that includes a dividend payment at $\tau$ is equal to $-\left(\mathrm{N}_{0} \mathrm{~S}_{0}+\mathrm{B}_{0}\right)$, where $\left(\mathrm{N}_{0}, \mathrm{~B}_{0}\right)$ are found from the program:

(P2)Min $\left\{\mathrm{N}_{0} \mathrm{~S}_{0}+\mathrm{B}_{0}\right\}$, subject to $\mathrm{RB}_{\mathrm{j}-1}\left(\omega_{\mathrm{j}}\right)-\mathrm{B}_{\mathrm{j}}\left(\omega_{\mathrm{j}}\right) \geq \phi\left(\mathrm{N}_{\mathrm{j}}\left(\omega_{\mathrm{j}}\right)-\mathrm{N}_{\mathrm{j}-1}\left(\omega_{\mathrm{j}}\right)\right) \mathrm{S}_{\mathrm{j}}\left(\omega_{\mathrm{j}}\right)$ for every $\mathrm{j} \leq \tau-1$ and for every path $\omega_{\mathrm{j}}$.

Suppose that (1) hold and that the situation is as depicted in Figure 1. Then at $j=\tau$ the constraint on $\mathrm{RB}_{\tau-1}$ is replaced by the following:

$$
\begin{aligned}
& \mathrm{RB}_{\tau-1} \geq \mathrm{X}+\phi\left(-1-\mathrm{N}_{\tau-1}\left(\omega_{\tau}\right)\right) \mathrm{S}_{\tau}\left(\omega_{\tau}\right), \mathrm{S}_{\tau}\left(\omega_{\tau}\right) \in\left\{\left[\mathrm{S}_{0} \mathrm{~d}^{\tau}, \mathrm{S}_{0} \mathrm{u}^{\tau}\right] \cap\left[\mathrm{S}_{\tau} ; \mathrm{S}_{\tau}\left(\omega_{\tau}\right) \geq \mathrm{S}_{\tau 2}\right]\right\} ; \\
& \mathrm{RB}_{\tau-1} \geq \mathrm{B}_{\tau \mathrm{b}}+\phi\left(-\mathrm{N}_{\tau-1}+\mathrm{N}_{\tau \mathrm{b}}\right)\left[\mathrm{S}_{\tau}\left(\omega_{\tau}\right)-\mathrm{D}\right]-\mathrm{DN}_{\tau-1}, \mathrm{~S}_{\tau}\left(\omega_{\tau}\right) \in\left\{\left[\mathrm{S}_{0} \mathrm{~d}^{\tau}, \mathrm{S}_{0} \mathrm{u}^{\tau}\right] \cap\left[\mathrm{S}_{\tau} ; \mathrm{S}_{\tau}\left(\omega_{\tau}\right) \leq \mathrm{S}_{\tau 1}\right]\right\} ;
\end{aligned}
$$

(14)

$$
\begin{aligned}
& \mathrm{RB}_{\tau-1}+\operatorname{Max}\left\{-\mathrm{X}-\phi\left(-1-\mathrm{N}_{\tau-1}\right) \mathrm{S}_{\tau}\left(\omega_{\tau}\right),-\mathrm{B}_{\tau \mathrm{b}}-\phi\left(-\mathrm{N}_{\tau-1}+\mathrm{N}_{\tau \mathrm{b}}\right)\left[\mathrm{S}_{\tau}\left(\omega_{\tau}\right)-\mathrm{D}\right]+\mathrm{DN} \mathrm{N}_{\tau-1}\right\} \geq 0, \\
& \mathrm{~S}_{\tau}\left(\omega_{\tau}\right) \in\left\{\left[\mathrm{S}_{0} \mathrm{~d}^{\tau}, \mathrm{S}_{0} \mathrm{u}^{\tau}\right] \cap\left[\mathrm{S}_{\tau 1}, \mathrm{~S}_{\tau 2}\right]\right\}
\end{aligned}
$$

The last condition can be rewritten as:

(14a) $\mathrm{RB}_{\tau-1} \geq \operatorname{Min}\left\{\mathrm{X}+\phi\left(-1-\mathrm{N}_{\tau-1}\right) \mathrm{S}_{\tau}\left(\omega_{\tau}\right), \mathrm{B}_{\tau \mathrm{b}}+\phi\left(\mathrm{N}_{\tau \mathrm{b}}-\mathrm{N}_{\tau-1}\right)\left[\mathrm{S}_{\tau}\left(\omega_{\tau}\right)-\mathrm{D}\right]-\mathrm{DN}_{\tau-1}\right\}$ $\mathrm{S}_{\tau}\left(\omega_{\tau}\right) \in\left\{\left[\mathrm{S}_{0} \mathrm{~d}^{\tau}, \mathrm{S}_{0} \mathrm{u}^{\tau}\right] \cap\left[\mathrm{S}_{\tau 1}, \mathrm{~S}_{\tau 2}\right]\right\}$. 
The first part in the RHS of (14a) corresponds to immediate and the second part to deferred exercise. Here, in contrast to the long call, not only is the terminal portfolio at $\tau$ unspecified, but the RHS of the constraint (14a), which is the minimum of two convex functions at each successor node, is not necessarily convex in $\mathrm{N}_{\tau-1}$. Hence, the key Lemma 5 and Theorem 1 of BLPS do not hold, implying that their results need to be re-examined within our context. Fortunately, convexity is restored when (2) does not hold, and a unique solution emerges when (1) holds. The following theorem $^{16}$ is the counterpart of Theorem 2 of BLPS and Theorem 4 of BV.

Theorem 3. If relations (1) hold then a unique replicating portfolio exists for the short call in the presence of a single constant dividend prior to expiration, which is also the optimal hedging portfolio.

Proof. See appendix.

As with the long call, the replicating portfolio at $\tau-1$ is rather complex. After identifying the early exercise boundary points at $\tau$, the portfolio replicates deferred exercise when $S_{\tau} \leq S_{\tau 1}$ for both successor nodes. It is given by the solution to the following system, which corresponds to (10a,b):

(15a) $\mathrm{u}(1-\mathrm{k}) \mathrm{S}_{\tau-1} \mathrm{~N}_{\tau-1}+\mathrm{RB}_{\tau-1}+\mathrm{kDN}_{\tau-1}=(1-\mathrm{k}) \mathrm{N}_{\tau \mathrm{b}}(\mathrm{u})\left(\mathrm{uS} \mathrm{S}_{\tau-1}-\mathrm{D}\right)+\mathrm{B}_{\tau \mathrm{b}}(\mathrm{u})$,

$(15 b) d(1+k) S_{\tau-1} N_{\tau-1}+R_{\tau-1}-k N_{\tau-1}=(1+k) N_{\tau b}(d)\left(d S_{\tau-1}-D\right)+B_{\tau b}(d)$

This portfolio is eventually replaced by one that replicates immediate exercise for an up move and deferred exercise for a down move. It is given by the solution of:

(16a) $\mathrm{u}(1-\mathrm{k}) \mathrm{S}_{\tau-1} \mathrm{~N}_{\tau-1}+\mathrm{RB}_{\tau-1}=\mathrm{X}-\mathrm{u}(1-\mathrm{k}) \mathrm{S}_{\tau-1}$,

(16b) (same as (15b)). 
Last, for higher nodes we have immediate exercise, with $\left(\mathrm{N}_{\tau-1}, \mathrm{~B}_{\tau-1}\right)=(-1, \mathrm{X})$, while (7b) yield the replicating portfolio for all $\mathrm{j} \in[0, \tau-2]$.

Thus, the presence of a dividend does not alter the essential conclusion of the BV and BLPS studies: when the transactions costs are "small", in the sense that (1) hold, perfect hedging can be achieved by option replication. Nonetheless, the type of replication involved here is considerably more complex than in the earlier studies, insofar as the optimal policy at the exdividend date is dependent on the stock price and the size of the dividend, in order to preserve the perfect-hedging requirement.

An approximate value for the call bid price in the presence of dividends can also be derived by the RGW procedure if $\tau$ is large and the dividend policy is a constant yield one, with an approach similar to the one used in the previous section. Indeed, as argued in BV (p. 279), the bid price in the absence of dividends can be approximated by a Black-Scholes formula with a modified variance equal to $\sigma^{2}[1-(2 \mathrm{k} V \tau) /(\sigma \sqrt{ } \mathrm{t})]$. Since our process is identical to that of BV for all $\mathrm{j}=1, \ldots, \tau-1$, and it was shown that the complications of the last transition to $\tau$ can be omitted for a large $\tau$, the bid price can be approximated by the expression $\mathrm{e}^{-\mathrm{rt}} \mathrm{E}\left[\operatorname{Max}\left\{\mathrm{S}_{\mathrm{t}}-\mathrm{X}, \mathrm{C}_{\mathrm{b}}\left((1-\gamma) \mathrm{S}_{\mathrm{t}}, \mathrm{t}_{1}-\mathrm{t}\right)\right\}\right]$. The call value is a Black-Scholes expression and the expectation is evaluated with a risk-neutral lognormal distribution, with a variance modified as above. Similarly, if the transaction cost parameter varies inversely with the number of binomial time periods, with $\mathrm{k}=\mathrm{\kappa} / \mathrm{h}$, the variance of the limiting lognormal process is equal to $\sigma^{2}[1-2 \kappa / \sigma]$.

The next case is when (2) hold. We know that in the absence of dividends the value of the optimal perfectly-hedging portfolio coincides with the Merton (1973) lower bound, $\operatorname{Max}\left\{\mathrm{S}_{0^{-}}\right.$ $\left.\mathrm{X} / \mathrm{R}^{\mathrm{T}}, 0\right\}$. Hence, $\left(\mathrm{N}_{\tau b}, \mathrm{~B}_{\tau b}\right)$ is equal to $\left(-1, \mathrm{X} / \mathrm{R}^{\mathrm{T}-\tau}\right)$ or to $(0,0)$. Also, we cannot any longer assume 
that at time $\tau$ the intermediary will choose either to exercise the option, or to restructure the hedging portfolio to the $\left(\mathrm{N}_{\tau b}, \mathrm{~B}_{\tau \mathrm{b}}\right)$ that corresponds to a starting price $\mathrm{S}_{\tau}$-D, since the optimal hedging portfolio is no longer independent of $\mathrm{N}_{\tau-1}$. The solution of this case is rather complex, but the ultimate result turns out to be not very useful. It is expressed by Theorem 4, whose proof is available from the authors on request.

Theorem 4. When both (2) and (9) hold the bid price of the call option in the presence of dividends is equal to either $\operatorname{Max}\left\{0, S_{0}-X / R^{\tau}\right\}$ or to $\operatorname{Max}\left\{0, S_{0}-X / R^{T}-D / R^{\tau}\right\}$, depending on which one of the second terms within braces is largest.

Theorem 4 basically implies that the bid price in the presence of a dividend is also equal to the Merton bound under either immediate or defered exercise policy, whichever is largest. This is the result that emerges when transaction costs become "too large" with respect to the binomial parameters. It forms the counterpart of the result of Soner et al (1995) for the long call, and PL for the short call when there are no dividends. Hence, the validity of relations (1) and (9) becomes crucial in assessing the significance of the various theorems proved in this paper. Given their importance, these relations will be discussed in the next section.

\section{Extensions, Discussion, and Numerical Examples}

All the results derived in this paper relied on the properties of the functions $C_{m}\left(S_{0}\right), C_{m+}\left(S_{0}\right)$, $\mathrm{C}_{\mathrm{m}-}\left(\mathrm{S}_{0}\right), \mathrm{m}=\mathrm{a}, \mathrm{b}$, derived in Lemmas $1-3$. It is the convexity of these functions and the size of their derivatives that establish the key configuration of the early exercise boundary shown in Figure 1. These properties also play a major role in the proofs of Theorems 1-3. 
For this reason the extension of the above results to more than one dividend to expiration is immediate and does not require a new formulation. It suffices to show that Lemmas 1-3 also hold for the functions $\mathrm{C}_{\mathrm{md}}\left(\mathrm{S}_{0}\right), \mathrm{C}_{\mathrm{md}+}\left(\mathrm{S}_{0}\right), \mathrm{C}_{\mathrm{md}-}\left(\mathrm{S}_{0}\right), \mathrm{m}=\mathrm{a}, \mathrm{b}$, the option ask and bid prices when there is one ex-dividend date prior to expiration. The proof relies on the solution of the systems $(10 \mathrm{a}, \mathrm{b})$ and (11a,b) for the long call $((15 a, b)$ and $(16 a, b)$ for the short call) at $\tau-1$, and the corresponding relations $(7 \mathrm{a}, \mathrm{b})$ for all times $\mathrm{j} \in[0, \tau-1)$, and is otherwise identical to that of Lemmas $1-3$. Hence, the algorithms derived in Theorems 1 and 3 are also valid recursively for any number of dividends till option expiration.

The inequality relations (1) are discussed at length in PL, where it is shown that for a constant $\mathrm{k}$ they are satisfied only for small sizes of the binomial tree when $\mathrm{u}, \mathrm{d}$ and $\mathrm{R}$ follow the expressions that tend to diffusion. In other words, under (12) both $\tau$ and T- $\tau$ must be "small" for (1) to hold.

Inequality set (9), though, is considerably more plausible, even for a constant k. Indeed, consider the following parameter values ${ }^{17}: \sigma=0.2, \mathrm{r}=0.1, \mathrm{~d}=\mathrm{u}^{-1}, \mathrm{k}=0.5 \%$. Assume a dividend yield $\mathrm{D} / \mathrm{S}_{\tau} \leq 0.1$, and consider values of $\mathrm{t} \tau$ satisfying (9). It can be easily seen that with these parameter values (9) is satisfied whenever $\sqrt{t}_{\mathrm{t}} \tau$ exceeds 0.00251 , or whenever $\tau<39,500$ price changes per quarter. This works out to more than one price change per minute, corresponding to binomial tree sizes far above those used in most practical applications.

Hence, as $\tau$ increases for a fixed $k$ we have the following successive regimes: a) (1) and (9) hold; b) (9) holds, but neither (1) nor (2) hold; c) both (2) and (9) hold; d) (2) holds but (9) is violated. In the absence of dividends (9) is irrelevant, and the optimal portfolios are found by 
relations (7a) for the ask price in all cases, while for the bid price they are given by relations (7b) under regime (a), by the Merton bound under regime (c), and by one or the other of these two alternatives under regime $(\mathrm{b})^{18}$. In the presence of dividends Theorems 1 and 2 are valid under regimes (a), (b) and (c), Theorem 3 holds under regime (a) and Theorem 4 under regime (c), while one or the other may hold under regime (b).

Last, under regime (d), if (9) is not satisfied, then the general approach of this paper continues to be valid, but none of the proofs of the theorems presented in this paper holds ${ }^{19}$. Restructuring optimally the hedge portfolio for both long and short calls may now yield results that have stockholdings lying outside the respective intervals $[0,1]$ and $[-1,0]$. While it would still be possible to derive results for such a case, the violation of (9) is, in our opinion, too rare an event to make it worth the effort.

We provide below some perfectly-hedged option bid and ask prices when there is one dividend prior to expiration, first for a fixed transaction cost parameter and a constant dividend, and then for a proportional dividend and a parameter $\mathrm{k}$ declining in proportion to the size of the binomial tree according to the Henrotte-Flesaker and Hughston assumption. The following parameter values were kept constant in all results: $\mathrm{S}=\$ 100 ; \mathrm{t}_{1}=0.25 ; \mathrm{t}=\mathrm{t}_{1} / 2 ; \sigma=0.2 ; \mathrm{r}=0.1$. For the constant $\mathrm{k}$ and $\mathrm{D}$ in Table $1 \mathrm{~T}$ is $40, \mathrm{D}=\$ 5$ and $\mathrm{k}=0.5 \%$. With the chosen values of the other parameters $\mathrm{k}=0.5 \%$ corresponds to the case where the inequalities (1) are satisfied. In our working paper (Perrakis and Lefoll, 1997b) results are also provided for $\mathrm{k}=2.5 \%$, when condition (2) is satisfied and the bid prices are equal to the Merton bound.

In Table 1 the columns $C_{a B}$ and $C_{b B}$ indicate the ask and bid prices under the Black (1975) assumption, as the maximum (for the ask) and the minimum (for the bid) of the call prices under 
early and deferred exercise for all stock prices at ex-dividend date ${ }^{20}$. The entry $\Delta \mathrm{C}_{\mathrm{d}}$ is the difference $\left(\mathrm{C}_{\mathrm{ad}}-\mathrm{C}_{\mathrm{bd}}\right)$ as percentage of the midpoint $\left(\mathrm{C}_{\mathrm{ad}}+\mathrm{C}_{\mathrm{bd}}\right) / 2$. The value-added of the new results presented in this paper consists of the comparison of $\mathrm{C}_{\mathrm{ad}}\left(\mathrm{C}_{\mathrm{bd}}\right)$ to $\mathrm{C}_{\mathrm{aB}}\left(\mathrm{C}_{\mathrm{bB}}\right)$.

As seen in the table below, and as expected from the computational algorithm, the introduction of dividends raises substantially in all cases the correct ask price $\mathrm{C}_{\mathrm{ad}}$ in comparison with the pseudo-American such price $\mathrm{C}_{\mathrm{aB}}$. The increase is most significant when the option is at- or slightly in-the-money. This rise, however, does not necessarily result in a wider bid/ask spread, because the bid price $\mathrm{C}_{\mathrm{bd}}$ rises even more than the ask price with respect to its pseudo-American value. Similarly, Table 1 shows that when (1) holds the pseudo-American bid/ask spread is almost always larger in both absolute and percentage terms than the correct spread. In other words, the presence of dividends when transactions costs are not very large raises the bid price more than the ask price, thus reducing the spread.

Table 1: Bid and ask call prices and spreads for $\mathrm{T}=40, \mathrm{k}=.5 \%$

Table 2, presents the ask and bid prices $\mathrm{C}_{\mathrm{ad}}$ and $\mathrm{C}_{\mathrm{bd}}$ computed under our algorithm with a transaction cost parameter $\mathrm{k}=\mathrm{\kappa} / \mathrm{t}_{1} / \mathrm{T}$, under the Henrotte-Flesaker and Hughston assumption. These values are then compared in Table 3 to the call prices of a conventional binomial model with dividends, with $\mathrm{k}=0$ but with modified volatilities equal to $\sigma \sqrt{ }(1+2 \kappa / \sigma)$ and $\sigma \sqrt{ }(1-2 \kappa / \sigma)$ for the ask and the bid respectively. The dividend policy here is of the constant yield type ${ }^{21}$ with $\gamma=5 \%$ and $\kappa$ was set equal to $0.5 \%$; the remaining parameters are as in Table 1 . Hence, the limiting case of $\mathrm{k}=0$ and modified volatilities yields prices $C_{a d}$ and $C_{b d}$ with respective volatilities equal to $0.2 \sqrt{ } 1.05$ and $0.2 \sqrt{ } 0.95$. 
Table 2: Bid and ask call prices for $\mathrm{k}=\mathrm{K} / \mathrm{t}_{1} / \mathrm{T}$

Table 3: Bid and ask call prices for $\mathrm{k}=0, \sigma=0.2 \sqrt{ } 1.05$ and $\sigma=0.2 \sqrt{ } .95$

It is clear that the entries in Tables 2 and 3 are very close to each other, generally within $\$ .01$ for both bid and ask. Further, there is a clear convergence to a value representing the continuous-time limit as the number of time subdivisions increases, with the limit essentially reached for $\mathrm{T}=50$ (see note 12). Such convergence was also observed in all our other simulation results (not reported here but available on request), in which $\sigma$ was varied between 0.10 and 0.30 , and $\mathrm{T}$ was varied between 0.10 and 0.40 . Hence, our algorithms represent the appropriate generalization of the binomial model for American options in the presence of dividends and transaction costs under the perfect hedging assumption.

\section{Conclusions}

This paper has presented a procedure for the computation of the perfectly-hedged bid and ask prices for an option on an asset with physical delivery when there are known dividends prior to expiration. The computational algorithms extended previous studies by Boyle and Vorst (1992), Bensaid et al (1992) and Perrakis and Lefoll (1997a). It was shown that the optimal perfect hedging policy corresponded to a form of replication, somewhat more complex than the usual replication of the positions of the two successor nodes of the binomial tree. This replication was always optimal for the ask price, but it was optimal for the bid price only if the key inequality set (1) held. 
The results were conditional on the key inequality set (9), containing restrictions on the binomial, transaction cost parameters, and dividend yield at the ex-dividend dates. These restrictions are weaker than the inequality set (1), which must be satisfied for the bid price to have a non-trivial value. Both (1) and (9) are usually satisfied if the dividend policy is of the constant yield type at ex-dividend date, and if the transaction cost parameter declines in proportion to the square root of the number of time periods. In such a case both ask and bid prices reach continuous-time limits with modified volatilities.

The results of this paper are for options with physical delivery of the underlying asset. An important extension in future research would be to cash-settlement options, such as index options. 


\section{$\underline{\text { Appendix }}$}

\section{Proof of Lemmas 1,2 and 3.}

All proofs use induction on $\mathrm{n}$. For $\mathrm{n}=1$ Lemmas 1 and 2 clearly hold, while for Lemma 3 the proof is virtually identical for all four functions; we shall present it in detail for the last two. For $n=1$ the replicating portfolio $\left(\mathrm{N}_{0 \mathrm{~b}}, \mathrm{~B}_{0 \mathrm{~b}}\right)$ is equal to $(-1, \mathrm{X} / \mathrm{R})$, or to $(0,0)$ when both $\mathrm{S}_{0} \mathrm{u}$ and $\mathrm{S}_{0} \mathrm{~d}$ are on the same side of $\mathrm{X} /(1-\mathrm{k})$. Assume that $\mathrm{X} /(1-\mathrm{k}) \in\left(\mathrm{S}_{0} \mathrm{~d}, \mathrm{~S}_{0} \mathrm{u}\right)$; then the solution of system (7b) yields a replicating portfolio $-\mathrm{N}_{\mathrm{ob}} \mathrm{S}_{0}=\left[\mathrm{S}_{0} \mathrm{u}(1-\mathrm{k})-\mathrm{X}\right] /[\mathrm{u}(1-\mathrm{k})-\mathrm{d}(1+\mathrm{k})], \quad \mathrm{B}_{0 b}=-\mathrm{N}_{0 b} \mathrm{~S}_{0} \mathrm{~d}(1+\mathrm{k}) / \mathrm{R}$, and by (1) it is clear that all parts of the lemma hold ${ }^{22}$ for both functions for $n=1$, QED.

Next comes the convexity proof, which is identical for all functions in Lemmas 1-3, and will again be carried out for the last two functions of Lemma 3. Assume that convexity holds for both replicating portfolios $\left(\mathrm{N}_{\mathrm{ji}}, \mathrm{B}_{\mathrm{ji}}\right), \mathrm{i}=1,2$, at time $\mathrm{j}$ and at nodes $\mathrm{u} \mathrm{S}_{\mathrm{j}}$ and $\mathrm{d} \mathrm{S}_{\mathrm{j}}$ respectively. Solving the system (7b) and re-arranging, we get the replicating portfolio $\left(\mathrm{N}_{\mathrm{j}}, \mathrm{B}_{\mathrm{j}}\right)$ at node $\mathrm{S}_{\mathrm{j}}$, which yields $-\left[(1-\mathrm{k}) \mathrm{N}_{\mathrm{j}} \mathrm{S}_{\mathrm{j}}+\mathrm{B}_{\mathrm{j}}\right]=-\left\{\alpha\left[\mathrm{N}_{\mathrm{j} 1} \mathrm{u}(1-\mathrm{k}) \mathrm{S}_{\mathrm{j}}+\mathrm{B}_{\mathrm{j} 1}\right]+(1-\alpha)\left[\mathrm{N}_{\mathrm{j} 2} \mathrm{~d}(1+\mathrm{k}) \mathrm{S}_{\mathrm{j}}+\mathrm{B}_{\mathrm{j} 2}\right]\right\} / \mathrm{R}$, where $\alpha \equiv[\mathrm{R}(1-\mathrm{k})-\mathrm{d}(1+\mathrm{k})] /$ $[\mathrm{u}(1-\mathrm{k})-\mathrm{d}(1+\mathrm{k})] \in[0,1]$. By the induction hypothesis both terms in brackets are non-negative, non-decreasing and convex in $\mathrm{uS}_{\mathrm{j}}$ and $\mathrm{dS}_{\mathrm{j}}$, implying that their convex combination is also convex in $S_{j}$; similar expressions hold for $-\left[(1+k) N_{j} S_{j}+B_{j}\right]$, QED.

The proof for the other two functions of Lemma 3 involving the ask price replicating portfolios, and for the functions $\mathrm{C}_{\mathrm{a}}\left(\mathrm{S}_{0}, \mathrm{n}\right)$ and $\mathrm{C}_{\mathrm{b}}\left(\mathrm{S}_{0}, \mathrm{n}\right)$ of Lemmas 1 and 2 is identical. Convexity is also sufficient for the proof of the derivative conditions in Lemmas 1 and 2, since when the option is always in-the-money both $\mathrm{C}_{\mathrm{a}}$ and $\mathrm{C}_{\mathrm{b}}$ are equal to $\mathrm{S}_{0}-\mathrm{X} / \mathrm{R}^{\mathrm{n}}$. Finally, the last part of Lemma 2 is a straightforward application of Lemma 2 of BLPS, QED. 
It remains now to show that $\mathrm{N}\left(\mathrm{S}_{0}\right)$ is non-decreasing and $\mathrm{B}\left(\mathrm{S}_{0}\right)$ is non-increasing for both ask and bid prices. Since the proof is identical, we present it only for the ask price and omit the subscripts for simplicity of presentation. Solving (7a) we find that $\mathrm{N}(\mathrm{S}) \sim\left[\mathrm{C}_{+}(\mathrm{Su})-\mathrm{C}_{-}(\mathrm{Sd})\right] / \mathrm{S}$. By the induction hypothesis $\mathrm{N}(\mathrm{dS})$ is non-decreasing in dS. Rewriting $\mathrm{C}_{+}(\mathrm{Su})-\mathrm{C}_{-}(\mathrm{Sd})=\left[\mathrm{C}_{+}(\mathrm{Su})-\right.$ $\left.\mathrm{C}_{+}(\mathrm{Sd})\right]+\left[\mathrm{C}_{+}(\mathrm{Sd})-\mathrm{C}_{-}(\mathrm{Sd})\right]$ and dividing both of them by $\mathrm{S}$, we observe that both are nondecreasing: the second one is proportional to $\mathrm{N}(\mathrm{dS})$ and the first one to $\left[\mathrm{C}_{+}(\mathrm{Su})-\mathrm{C}_{+}(\mathrm{Sd})\right] /[\mathrm{S}(\mathrm{u}-$ d)], with the latter being non-decreasing by the convexity of the $\mathrm{C}_{+}$function, QED.

The proof for $\mathrm{B}\left(\mathrm{S}_{0}\right)$ is similarly based on the convexity proven in the first part. From (7a) we have $B(S) \sim u(1+k) C_{-}(S d)-d(1-k) C_{+}(S u)$. Letting a prime denote the derivative, we have by induction that $\mathrm{B}^{\prime}(\mathrm{Sd})$ and $\mathrm{B}^{\prime}(\mathrm{Su})$ are negative. Hence, $\mathrm{B}^{\prime}(\mathrm{S})<0 \Leftrightarrow(1+\mathrm{k}) \mathrm{C}_{-}{ }^{\prime}(\mathrm{Sd})<(1-\mathrm{k}) \mathrm{C}_{+}{ }^{\prime}(\mathrm{Su})$. The right-hand-side (RHS) exceeds $(1-\mathrm{k})(1+\mathrm{k}) \mathrm{C}^{\prime}(\mathrm{Su})$, while $\mathrm{C}_{.}$' $(\mathrm{Sd})$ is less than $(1-\mathrm{k}) \mathrm{C}^{\prime}(\mathrm{Sd})$, thus reducing the relation to $\mathrm{C}^{\prime}(\mathrm{Sd})<\mathrm{C}^{\prime}(\mathrm{Su})$, which obviously holds, QED.

\section{Proof of Theorem 1.}

Theorem 1 corresponds to Theorems 1 and 2 of our working paper (Perrakis and Lefoll, 1997b). Only a summary of the proofs of these two theorems will be given here. We first show that the optimal stockholdings $\mathrm{N}_{\tau-1} *$ at any node are in the interval $[0,1]$. At $\mathrm{j}=\tau-1$ we derive $\mathrm{Q}_{\tau \text { - }}$ ${ }_{1}\left(\mathrm{~N}_{\tau-2}, \mathrm{~S}_{\tau-1}\right)$ by solving the program (4) subject to (5), where the functions $\mathrm{Q}_{\tau}\left(\mathrm{N}_{\tau-1}, \mathrm{u} \mathrm{S}_{\tau-1}\right)$ and $\mathrm{Q}_{\tau}\left(\mathrm{N}_{\tau-1}, \mathrm{dS}_{\tau-1}\right)$ are given by the appropriate expressions in the RHS of $(8 \mathrm{a}, \mathrm{b}, \mathrm{c})$. We need to show that $\mathrm{Q}_{\tau}\left(0, \mathrm{u} \mathrm{S}_{\tau-1}\right) \geq \mathrm{Q}_{\tau}\left(0, \mathrm{~d} \mathrm{~S}_{\tau-1}\right)$ and $\mathrm{Q}_{\tau}\left(1, \mathrm{uS} \mathrm{S}_{\tau-1}\right) \leq \mathrm{Q}_{\tau}\left(1, \mathrm{~d} \mathrm{~S}_{\tau-1}\right)$, since we know that $\mathrm{N}_{\tau \mathrm{a}} \in[0,1]$ always. In such a case the slope of the binding constraint as a function of $\mathrm{N}_{\tau-1}$ in (5) would be either $-u S_{\tau-1}(1+k)$ or $-u S_{\tau-1}(1+k)+D k$ for $N_{\tau-1}=0$-, both of which are less than $-\mathrm{R}(1+\mathrm{k}) \mathrm{S}_{\tau-1}$ in view of (9), thus yielding an $\mathrm{N}_{\tau-1}$ * that is $\geq 0$ for all $\mathrm{N}_{\tau-2} \leq 0$; similarly, the slope at $\mathrm{N}_{\tau-1}=1+$ would be 
greater than $-\mathrm{R}(1-\mathrm{k}) \mathrm{S}_{\tau-1}$, yielding $\mathrm{N}_{\tau-1} * \leq 1$. The demonstration relies heavily on the convexity results of Lemmas 1,2 and 3 and is straightforward but tedious because of the various cases arising out of the different intervals of $\mathrm{S}_{\tau}$; it will be omitted.

Next we want to show that at time $\tau-1$ the conditions of Theorem 3 of BLPS hold for the unique optimal portfolio $\left(\mathrm{N}_{\tau-1}{ }^{*}, \mathrm{~B}_{\tau-1}{ }^{*}\right)$, since under these conditions program (4)-(6) yields a unique replicating portfolio for all $\mathrm{j} \in[0, \tau-1]$. Hence, we must show that the convex functions $\mathrm{Q}_{\tau}\left(\mathrm{N}_{\tau-1}, \mathrm{uS} \mathrm{S}_{\tau-1}\right)$ and $\mathrm{Q}_{\tau}\left(\mathrm{N}_{\tau-1}, \mathrm{~d} \mathrm{~S}_{\tau-1}\right)$ intersect at a single value of $\mathrm{N}_{\tau-1}$, which defines $\left(\mathrm{N}_{\tau-1}{ }^{*}, \mathrm{~B}_{\tau-1}{ }^{*}\right)$. We also have to show that $\mathrm{N}_{\tau-1} *$ is non-decreasing and $\mathrm{B}_{\tau-1} *$ is non-increasing in $\mathrm{S}_{\tau-1}$, and that the optimal portfolios at any two successive values of $S_{\tau-1}$ satisfy a certain technical condition (condition (6) of BLPS). It suffices to provide the proof for points $S_{\tau} \in\left(S_{\tau 1}, S_{\tau 2}\right)$ or $S_{\tau} \in\left(S_{\tau 3}, \infty\right)$, since this is the most general case.

Consider two consecutive points $\mathrm{A}$ and $\mathrm{B}$ at $\tau-1$ and their successor points $1=1,2,3$ in the binomial tree, as in Figure A1(a), and let $S_{1}$ denote the value of $S_{\tau}$ at point 1 , with the $S_{1}$ 's lying in the indicated intervals. As argued above, $\mathrm{Q}_{\tau}\left(0, \mathrm{~S}_{1}\right) \geq \mathrm{Q}_{\tau}\left(0, \mathrm{~S}_{2}\right) \geq \mathrm{Q}_{\tau}\left(0, \mathrm{~S}_{3}\right)$, with the inequalities holding strictly for the interval of values of $S_{\tau}$ that we are considering. The constraints $(8 a, b, c)$ define functions $\mathrm{Q}_{\tau}\left(\mathrm{N}_{\tau-1}, \mathrm{~S}_{\tau}\right)$ that have the piecewise linear forms shown in Figure $\mathrm{A} 1(\mathrm{bc})$, with the slope of the steeper line(s) being $-(1+\mathrm{k}) \mathrm{S}_{\tau}$ or $-(1+\mathrm{k}) \mathrm{S}_{\tau}+\mathrm{kD}$, that of the flatter line $-(1-k) S_{\tau}-k D$, and with the last kink at a value of $N_{\tau-1}$ that is greater than or equal to the corresponding stockholding $\mathrm{N}_{\tau \mathrm{a}}$. Our theorem is easily seen to hold if it can be shown that the functions $\mathrm{Q}_{\tau}\left(\mathrm{N}_{\tau-1}, \mathrm{u} \mathrm{S}_{\tau-1}\right)$ and $\mathrm{Q}_{\tau}\left(\mathrm{N}_{\tau-1}, \mathrm{dS}_{\tau-1}\right)$ intersect at a single value of $\mathrm{N}_{\tau-1}$, defined by the steeper line(s) of the u-function and the flattest line of the d-function, as in Figure A1(d). By (9) that value would be $\mathrm{N}_{\tau-1}$ *, the optimal $\mathrm{N}_{\tau-1}$ in the minimization problem (4) subject to (5), 
and it would lie between the stockholdings $\mathrm{N}_{\tau \mathrm{a}}$ corresponding to the successor $\mathrm{u}$ - and d-nodes in the binomial tree. Further, the sequence of portfolios $\left(\mathrm{N}_{\tau-1}{ }^{*}, \mathrm{~B}_{\tau-1}{ }^{*}\right)$ along the successive nodes $\mathrm{A}$ and B of the binomial tree at time $\tau-1$ would satisfy the conditions of the BLPS Theorem 3 . Indeed, it is clear from Figure $A 1(d)$ that $N_{\tau-1} *(A) \geq N_{\tau-1} *(B), B_{\tau-1} *(A) \leq B_{\tau-1} *(B)$, while condition (6) of Theorem 3 of BLPS corresponds to d(1-k) $\leq R\left[B_{\tau-1} *(B)-B_{\tau-1} *(A)\right] / S_{A}\left[N_{\tau-1} *(A)-\right.$ $\left.\mathrm{N}_{\tau-1} *(\mathrm{~B})\right] \leq \mathrm{u}(1+\mathrm{k})$. It is clearly satisfied, since the slope of the line BA in Figure A1(d) lies between the two lines that bracket it to the left of point $A$, and whose slopes are $-S_{A} d(1-k)-k D$ and $-\mathrm{S}_{\mathrm{A}} \mathrm{u}(1+\mathrm{k})+\mathrm{kD}$.

\section{Figure A1}

The most general case is when both $\mathrm{Q}_{\tau}\left(\mathrm{N}_{\tau-1}, \mathrm{u} \mathrm{S}_{\tau-1}\right)$ and $\mathrm{Q}_{\tau}\left(\mathrm{N}_{\tau-1}, \mathrm{~d} \mathrm{~S}_{\tau-1}\right)$ are given by (8c), ie. are both equal to $\operatorname{Max}\left\{\mathrm{W}_{\mathrm{a}}\left(\mathrm{N}_{\tau-1}, \mathrm{~S}_{\tau}\right), \mathrm{W}_{\mathrm{b}}\left(\mathrm{N}_{\tau-1}, \mathrm{~S}_{\tau}\right)\right\}$. For $\mathrm{N}_{\tau-1} \in[0,1] \mathrm{W}_{\mathrm{a}}\left(\mathrm{N}_{\tau-1}, \mathrm{uS} \mathrm{S}_{\tau-1}\right)$ $\geq \mathrm{W}_{\mathrm{b}}\left(\mathrm{N}_{\tau-1}, \mathrm{dS}_{\tau-1}\right)$, with the two functions being equal to $-\mathrm{X}$ at $\mathrm{N}_{\tau-1}=1$, and the inequality being strict for $\mathrm{N}_{\tau-1} \in[0,1)$. It suffices, therefore, to show that the steepest part of $\mathrm{W}_{\mathrm{b}}\left(\mathrm{N}_{\tau-1}, \mathrm{u} \mathrm{S}_{\tau-1}\right)$ intersects with the flattest part of $\mathrm{W}_{\mathrm{b}}\left(\mathrm{N}_{\tau-1}, \mathrm{dS}_{\tau-1}\right)$, as in Figure $\mathrm{A} 1(\mathrm{~d})$. Since $\mathrm{N}_{\tau \mathrm{a}}(\mathrm{u}) \geq \mathrm{N}_{\tau \mathrm{a}}(\mathrm{d})$ and $\mathrm{B}_{\tau \mathrm{a}}(\mathrm{u}) \leq \mathrm{B}_{\tau \mathrm{a}}(\mathrm{d})$, it suffices to show that $\mathrm{W}_{\mathrm{b}}\left(\mathrm{N}_{\tau \mathrm{a}}(\mathrm{d}), \mathrm{u} \mathrm{S}_{\tau-1}\right) \geq \mathrm{W}_{\mathrm{b}}\left(\mathrm{N}_{\tau \mathrm{a}}(\mathrm{d}), \mathrm{d} \mathrm{S}_{\tau-1}\right)$, and/or that $\mathrm{W}_{\mathrm{b}}\left(\mathrm{N}_{\tau \mathrm{a}}(\mathrm{u}), \mathrm{dS}_{\tau-1}\right) \geq \mathrm{W}_{\mathrm{b}}\left(\mathrm{N}_{\tau \mathrm{a}}(\mathrm{u}), \mathrm{u} \mathrm{S}_{\tau-1}\right)$. The proof is again straightforward and will be omitted; it uses induction on $\mathrm{T}-\tau$, as well as the convexity results of Lemma 3.

\section{Proof of Theorem 2.}

As shown in BV pp. 274-276, the evaluation of the replicating portfolio in the absence of dividends corresponds to the discounted expectation of the call option value at expiration under 
a modified Markovian process, in which the transition probabilities depend on the previous move. Adopting similar notation to $\mathrm{BV}$, we set these transition probabilities in matrix form $\mathrm{P}$, where:

(A1) $P \equiv\left[\begin{array}{cc}p_{u} & p_{d} \\ 1-p_{u} & 1-p_{d}\end{array}\right], p_{u}=[R(1+k)-\bar{d}] /[\bar{u}-\bar{d}], p_{d}=[R(1-k)-\bar{d}] /[\bar{u}-\bar{d}]$,

and $\overline{\mathrm{u}}=\mathrm{u}(1+\mathrm{k}), \overline{\mathrm{d}}=\mathrm{d}(1-\mathrm{k})$; the initial transition takes place with probabilities $\mathrm{p}$ and 1-p for up and down moves, where $\mathrm{p}=[\mathrm{R}-\overline{\mathrm{d}}] /[\overline{\mathrm{u}}-\overline{\mathrm{d}}]$. In (A1) $\mathrm{p}_{\mathrm{u}}$ and $\mathrm{p}_{\mathrm{d}}$ are the probabilities of an up move, given that the previous move was, respectively, an up and a down move. The Markovian process consists of a sequence of random variables $\mathrm{x}_{1}, \ldots, \mathrm{x}_{\tau}$, each one of which can have only two states with values $\operatorname{lnu}$ and lnd. The stock price $S_{\tau}$ is equal to $S_{0} e^{Y}$, where $Y=\Sigma x_{j}$. Let also $Y_{\tau-1}=$ $\mathrm{x}_{1}+\ldots+\mathrm{x}_{\tau-1}$, and $\mathrm{Y}_{1}=\operatorname{Max}\left\{\mathrm{Y}_{\tau-1}: \mathrm{Y}_{\tau-1} \leq \ln \left(\mathrm{S}_{\tau-1,1} / \mathrm{S}_{0}\right)\right\}, \mathrm{Y}_{2}=\operatorname{Min}\left\{\mathrm{Y}_{\tau-1}: \mathrm{Y}_{\tau-1} \geq \ln \left(\mathrm{S}_{\tau-1,2} / \mathrm{S}_{0}\right)\right\}$

In our case the Markovian process is identical to that of $B V$ for all $j=1, \ldots, \tau-1$. At $\tau-1$, however, the matrix of transition probabilities will change depending on the value of $\mathrm{Y}_{\tau-1}$. Setting $\mathrm{D}=\gamma \mathrm{S}_{\tau}$, we note that for $\mathrm{Y}_{\tau-1} \leq \mathrm{Y}_{1}$ and $\mathrm{Y}_{\tau-1} \in\left(\mathrm{Y}_{1}, \mathrm{Y}_{2}\right)$ the matrix $\mathrm{P}$ must be replaced by $\mathrm{P}_{1}$ and $\mathrm{P}_{2}$ respectively ${ }^{23}$, where:

(A2) $P_{1}=\left[\begin{array}{cc}\underline{p_{u}} & \underline{p_{d}} \\ 1-\underline{p_{u}} & 1-\underline{p_{d}}\end{array}\right], P_{2}=\left[\begin{array}{cc}\underline{p_{u^{\prime}}} & \underline{p_{d^{\prime}}} \\ 1-\underline{p_{u^{\prime}}} & 1-\underline{p_{d^{\prime}}}\end{array}\right]$,

and $\underline{\mathrm{p}}_{\mathrm{u}}=[\mathrm{R}(1+\mathrm{k})-\overline{\mathrm{d}}] /[\mathrm{u}(1+\underline{\mathrm{k}})-\mathrm{d}(1-\underline{\mathrm{k}})], \mathrm{p}_{\mathrm{u}}{ }^{\prime}=[\mathrm{R}(1+\mathrm{k})-\overline{\mathrm{d}}] /[\overline{\mathrm{u}}-\mathrm{d}(1-\underline{\mathrm{k}})], \underline{\mathrm{k}} \equiv \mathrm{k}(1-\gamma)$, while $\mathrm{p}_{\mathrm{d}}, \underline{\mathrm{p}}_{\mathrm{d}}^{\prime}$ simply replace $\mathrm{R}(1+\mathrm{k})$ by $\mathrm{R}(1-\mathrm{k})$ in the numerators. As for the terminal positions at $\tau$, they correspond, 
as argued earlier, to immediate or deferred exercise for $S_{\tau-1}$ outside the interval $\left(S_{\tau-1,1}, S_{\tau-1.2}\right)$, and to immediate exercise for an up move and deferred exercise for a down move otherwise. Analytically, therefore, the option ask price $C_{a d}$ is given by an expectation with respect to the adjusted process, in an expression similar to (10) of BV:

(A3) $\mathrm{C}_{\mathrm{ad}}=\mathrm{R}^{-\tau} \mathrm{E}\left\{\operatorname{Max}\left[\left(1+\underline{\mathrm{x}}_{\tau} \mathrm{k}\right) \mathrm{S}_{0} \mathrm{e}^{\mathrm{Y}}-\mathrm{X}, \mathrm{B}_{\tau \mathrm{a}}+\left(1+\underline{x}_{\tau} \mathrm{k}\right) \mathrm{N}_{\tau \mathrm{a}} \mathrm{S}_{0}(1-\gamma) \mathrm{e}^{\mathrm{Y}}\right]\right\}$,

where $\underline{\mathrm{x}}_{\tau}=1$ if $\mathrm{x}_{\tau}=\ln u$ and $\underline{\mathrm{x}}_{\tau}=-1$ if $\mathrm{x}_{\tau}=\operatorname{lnd}$, and the adjusted process is identical to the one described in BV except when the logarithmic returns $Y_{\tau-1}$ are such that $Y_{\tau-1} \leq Y_{1}$ and $\mathrm{Y}_{\tau-1} \in\left(\mathrm{Y}_{1}, \mathrm{Y}_{2}\right)$, when the matrix $\mathrm{P}$ is replaced by $\mathrm{P}_{1}$ and $\mathrm{P}_{2}$ respectively.

For the limiting process we consider the binomial model given by (12) and we assume $t=1$ for simplicity. We then examine the limiting value of (A3) when $\tau$ becomes large. For $k=0$ expression (A3) becomes the value of an American call option with a single proportional dividend payable at $\tau$ under the binomial model. To prove the theorem we first show that for a large $\tau$ an approximate limiting lognormal distribution of the stock price $S_{\tau}$ exists under our process, similar to the limiting distribution of (12) but incorporating the transactions costs. The following result allows us to use directly the derivations of the no-dividend case, as in BV, pp.276-278.

Lemma 4. The random variable $\mathrm{Y}=\mathrm{x}_{1}+\ldots+\mathrm{x}_{\tau}$ of expression (13) has the same asymptotic behaviour for large $\tau$ and small $\mathrm{k}$ as the corresponding random variable $\underline{\mathrm{Y}}$ of the no-dividend case, with:

(A4) $\mathrm{E}(\mathrm{Y})=\mathrm{r}-\operatorname{Var}(\mathrm{Y}) / 2+\mathrm{O}(1 / \sqrt{ } \tau)+\mathrm{O}\left(\mathrm{k}^{2}\right), \operatorname{Var}(\mathrm{Y})=\sigma^{2}\left\{1+\mathrm{O}\left(\mathrm{k}^{2}\right)+\left[2 \mathrm{k} / \sigma+\mathrm{O}\left(\mathrm{k}^{3}\right)\right] \sqrt{ } \tau\right\}+\mathrm{O}(1 / \sqrt{ } \tau)$. 


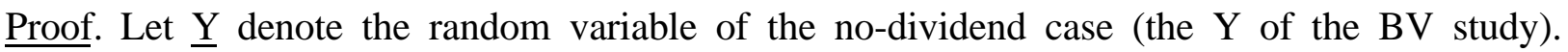
Clearly, since $\mathrm{Y}=\mathrm{Y}_{\tau-1}+\mathrm{x}_{\tau}, \mathrm{Y}$ and $\underline{\mathrm{Y}}$ differ only insofar as the last step $\mathrm{x}_{\tau}$ takes place with transition matrix $\mathrm{P}_{1}, \mathrm{P}_{2}$ or $\mathrm{P}$ depending on the value of $\mathrm{Y}_{\tau-1}$, instead of $\mathrm{P}$ always. Rewriting $\mathrm{p}_{\mathrm{u}}=[\mathrm{R}(1+\mathrm{k})-\mathrm{d}(1-\mathrm{k})] /[\mathrm{u}(1+\mathrm{k})-\mathrm{d}(1-\mathrm{k})-\gamma \mathrm{k}(\mathrm{u}+\mathrm{d})]$ and expanding $\mathrm{u}+\mathrm{d}=2\left[1+\sigma^{2}(1 / \tau) / 2+\mathrm{O}\left(\tau^{-3 / 2}\right)\right]$, we can rewrite $\mathrm{p}_{\mathrm{u}}$ as $[\mathrm{R}(1+\mathrm{k})-\mathrm{d}(1-\mathrm{k})][\mathrm{u}(1+\mathrm{k})-\mathrm{d}(1-\mathrm{k})-\gamma \mathrm{k}(\mathrm{u}+\mathrm{d})] /\left[[\mathrm{u}(1+\mathrm{k})-\mathrm{d}(1-\mathrm{k})]^{2}-\mathrm{O}\left(\mathrm{k}^{2}\right)-\mathrm{O}(\mathrm{k} / \tau)\right]$, which implies that $\underline{p}_{u} \approx p_{u}[1+2 k \gamma /[u(1+k)-d(1-k)]+O(1 / \tau)]=p_{u}\left(1+\lambda_{1}\right)$. Expanding the $u$ and $d$ terms in the denominator of $\lambda_{1}$, we find that $\lambda_{1}=[\gamma \mathrm{k}+\mathrm{O}(1 / \tau)] /[\mathrm{k}+\sigma \sqrt{ } 1 / \tau+\mathrm{O}(1 / \tau)] \approx \gamma \mathrm{k} /[\mathrm{k}+\sigma \sqrt{ } 1 / \tau]$, which is $<\gamma$. Similarly, we have $\mathrm{p}_{\mathrm{d}}=\mathrm{p}_{\mathrm{d}}\left(1+\lambda_{1}\right)$, while $\mathrm{p}_{\mathrm{u}}^{\prime}=[\mathrm{R}(1+\mathrm{k})-\mathrm{d}(1-\mathrm{k})] /[\mathrm{u}(1+\mathrm{k})-\mathrm{d}(1-\mathrm{k})-\gamma \mathrm{kd}]$. Expanding $\mathrm{d}$ in the term $\gamma \mathrm{kd}$ in the denominator and following the same procedure as with $\mathrm{p}_{\mathrm{u}}$, we get $\mathrm{p}_{\mathrm{u}^{\prime}} \approx \mathrm{p}_{\mathrm{u}}\left(1+\lambda_{2}\right)$, where $\lambda_{2}=\gamma \mathrm{k} /[2(\mathrm{k}+(1+\mathrm{k}) \sigma \sqrt{ } 1 / \tau)]<\lambda_{1} / 2$; similarly, $\mathrm{p}_{\mathrm{d}}^{\prime} \approx \mathrm{p}_{\mathrm{d}}\left(1+\lambda_{2}\right)$.

To find $\mathrm{E}(\mathrm{Y})$ and $\operatorname{Var}(\mathrm{Y})$ we replace $\mathrm{p}_{\mathrm{u}}$ and $\mathrm{p}_{\mathrm{u}}{ }^{\prime}$ by their asymptotic approximations into the transition matrices $\mathrm{P}_{1}$ and $\mathrm{P}_{2}$ and consider the distributions of $\underline{Y}$ and $\mathrm{Y}$. Since $\mathrm{Y}_{\tau-1}$ is common to both these random variables, which differ only whenever $\mathrm{Y}_{\tau-1}<\mathrm{Y}_{2}$, we consider the following events $i=1, \ldots, 6$, with corresponding probabilities $\pi_{i}$ and expectations $E_{i} \equiv E\left[Y_{\tau-1}\right.$ event i occurs]: $\left\{\mathrm{Y}_{\tau-1} \leq \mathrm{Y}_{1}\right.$, last event at $\tau-1$ is an up move $\} ;\left\{\mathrm{Y}_{\tau-1} \leq \mathrm{Y}_{1}\right.$, last event at $\tau-1$ is a down move $\} ;\left\{\mathrm{Y}_{\tau-1} \in\left(\mathrm{Y}_{1}, \mathrm{Y}_{2}\right)\right.$, last event at $\tau-1$ is an up move $\} ;\left\{\mathrm{Y}_{\tau-1} \in\left(\mathrm{Y}_{1}, \mathrm{Y}_{2}\right)\right.$, last event at $\tau-1$ is a down move $\} ;\left\{\mathrm{Y}_{\tau-1} \geq \mathrm{Y}_{2}\right.$, last event at $\tau-1$ is an up move $\} ;\left\{\mathrm{Y}_{\tau-1} \geq \mathrm{Y}_{2}\right.$, last event at $\tau-1$ is a down move . Let also $\mathrm{E} \equiv \mathrm{E}\left(\mathrm{Y}_{\tau-1}\right)$. Then we have:

$$
\begin{gathered}
\mathrm{E}(\mathrm{Y})=\mathrm{E}+\left(\pi_{1}+\pi_{3}+\pi_{5}\right)\left[\mathrm{p}_{\mathrm{u}} \operatorname{lnu}+\left(1-\mathrm{p}_{\mathrm{u}}\right) \operatorname{lnd}\right]+\left(\pi_{2}+\pi_{4}+\pi_{6}\right)\left[\mathrm{p}_{\mathrm{d}} \operatorname{lnu}+\left(1-\mathrm{p}_{\mathrm{d}}\right) \operatorname{lnd}\right] \\
+\lambda_{1}(\operatorname{lnu}-\operatorname{lnd})\left(\pi_{1} \mathrm{p}_{\mathrm{u}}+\pi_{2} \mathrm{p}_{\mathrm{d}}\right)+\lambda_{2}(\operatorname{lnu}-\operatorname{lnd})\left(\pi_{3} \mathrm{p}_{\mathrm{u}}+\pi_{4} \mathrm{p}_{\mathrm{d}}\right) \\
=\mathrm{E}(\underline{\mathrm{Y}})+2 \sigma \sqrt{ } 1 / \tau\left[\lambda_{1}\left(\pi_{1} \mathrm{p}_{\mathrm{u}}+\pi_{2} \mathrm{p}_{\mathrm{d}}\right)+\lambda_{2}\left(\pi_{3} \mathrm{p}_{\mathrm{u}}+\pi_{4} \mathrm{p}_{\mathrm{d}}\right)\right] .
\end{gathered}
$$


Since the last term in the RHS of (A5) is clearly $\mathrm{O}(1 / \sqrt{ } \tau)$, the first part of our Lemma 4 follows directly from Lemma 2 of BV, QED.

A similar approach is used for $\operatorname{Var} Y$. Let $\underline{Y}=Y_{\tau-1}+x_{\tau}{ }^{\prime}$, where $x_{\tau}{ }^{\prime}$ differs from $x_{\tau}$ only by the fact that the coefficients $\lambda_{i}, i=1,2$, are equal to zero in the transition probability matrices $\mathrm{P}_{1}$ and $\mathrm{P}_{2}$. Since $\operatorname{Var} Y=\operatorname{Var} \mathrm{Y}_{\tau-1}+\operatorname{Varx}_{\tau}+2 \operatorname{Cov}\left(\mathrm{Y}_{\tau-1}, \mathrm{x}_{\tau}\right)$, we evaluate directly the $\operatorname{Var} \mathrm{x}_{\tau}$ and $\operatorname{Cov}\left(\mathrm{Y}_{\tau-1}, \mathrm{x}_{\tau}\right)$ terms. We get, by direct substitution:

$$
\begin{aligned}
\operatorname{Varx}_{\tau}= & \operatorname{Varx}_{\tau}{ }^{\prime}-4 \sigma^{2} \tau^{-1}\left[\lambda_{1}^{2}\left(\pi_{1} p_{u}^{2}+\pi_{2} p_{d}^{2}\right)+\lambda_{2}^{2}\left(\pi_{3} p_{u}^{2}+\pi_{4} p_{d}^{2}\right)\right. \\
& \left.+p_{u}\left(2 p_{u^{-}}-1\right)\left(\lambda_{1} \pi_{1}+\lambda_{2} \pi_{3}\right)+p_{d}\left(2 p_{d}-1\right)\left(\lambda_{1} \pi_{2}+\lambda_{2} \pi_{4}\right)\right] \\
= & \operatorname{Varx}_{\tau}{ }^{\prime}+O(1 / \tau),
\end{aligned}
$$

implying that the contribution of the terms containing the $\lambda_{i}{ }^{\prime} s$ is $O(1 / \tau)$. Further, since $\operatorname{Var} x_{\tau}^{\prime}=\operatorname{Cov}\left(x_{\tau}^{\prime}, x_{\tau}{ }^{\prime}\right)$, we get from the BV eqation (A14) that $\operatorname{Varx}_{\tau}{ }^{\prime}=\mathrm{p}_{\tau}\left(1-\mathrm{p}_{\tau}\right)(\operatorname{lnu}-\operatorname{lnd})^{2}=4 \mathrm{p}_{\tau}(1-$ $\left.\mathrm{p}_{\tau}\right) \sigma^{2} / \tau$. However, the term $\mathrm{p}_{\tau}\left(1-\mathrm{p}_{\tau}\right)$ can be evaluated from the BV expressions (A17) and (A25), which yield ${ }^{24}$ (in a modified $\mathrm{BV}$ notation) that $\mathrm{p}_{\tau}\left(1-\mathrm{p}_{\tau}\right)=[\mathrm{p}(1-2 \Theta)+\Theta][(1-\mathrm{p})(1-2 \Theta)-$ $\Theta]\left[\mathrm{k}^{2}+\mathrm{O}(1 / \tau)+\mathrm{O}(\mathrm{k} / \sqrt{ } \tau)\right] \leq\left[\mathrm{k}^{2}+\mathrm{O}(1 / \tau)+(\mathrm{k} / \sqrt{ } \tau)\right] / 4$, where $\Theta=\mathrm{Rk} /(\overline{\mathrm{u}}-\overline{\mathrm{d}})$. Hence, $\operatorname{Varx}_{\tau}{ }^{\prime}$ is less than or equal to $\sigma^{2} / \tau$ times a term that is at $\operatorname{most}^{25} \mathrm{O}\left(\mathrm{k}^{2}\right)$, implying that $\operatorname{Varx}_{\tau}=\sigma^{2} \tau^{-1}\left[\mathrm{O}\left(\mathrm{k}^{2}\right)-\mathrm{f}\left(\lambda_{1}, \lambda_{2}\right)\right]$, where $\mathrm{f}$ is a quadratic function with $\mathrm{f}(0,0)=0$, QED.

The covariance term is more complicated. We shall show that $\operatorname{Cov}\left(\mathrm{Y}_{\tau-1}, \mathrm{X}_{\tau}\right)=\operatorname{Cov}\left(\mathrm{Y}_{\tau-1}, \mathrm{X}_{\tau}{ }^{\prime}\right)+$ $\mathrm{O}(1 / \sqrt{ } \tau)$, first by isolating the term containing the $\lambda_{\mathrm{i}}$ 's, then by showing that its contribution to the covariance is of the order $\mathrm{O}(1 / \sqrt{ } \tau)$. 
We first observe that inequality (9) implies that $\gamma \mathrm{k}$ is less than a term that is $\mathrm{O}(1 / \sqrt{ } \tau)$. Under the constant dividend yield assumption (9) takes the form $\mathrm{u}(1+\underline{\mathrm{k}})>\mathrm{R}(1+\mathrm{k}), \mathrm{R}(1-\mathrm{k})>\mathrm{d}(1-\underline{\mathrm{k}})$, where $\underline{k}=\mathrm{k}(1-\gamma)$. Expanding the first of these inequalities we get $\gamma \mathrm{k}(1+\sigma / \sqrt{ } \tau)<(1+\mathrm{k}) \sigma / \sqrt{ } \tau+\mathrm{O}(1 / \tau)$, or $\gamma \mathrm{k}<(1+\underline{\mathrm{k}}) \sigma / \sqrt{ } \tau=\mathrm{O}(1 / \sqrt{ } \tau)$. Hence, $\gamma \mathrm{k}$ is $\mathrm{O}(1 / \sqrt{ } \tau)$, a fact that will be used in the subsequent proof.

Evaluating the $\operatorname{Cov}\left(\mathrm{Y}_{\tau-1}, \mathrm{x}_{\tau}\right)$ directly, we get, after replacing lnu and lnd,

$$
\begin{gathered}
\operatorname{Cov}\left(\mathrm{Y}_{\tau-1}, \mathrm{x}_{\tau}\right)=\operatorname{Cov}\left(\mathrm{Y}_{\tau-1}, \mathrm{x}_{\tau}{ }^{\prime}\right)+2\left\{\lambda_{1}\left[\mathrm{p}_{\mathrm{u}} \pi_{1}\left(\mathrm{E}_{1}-\mathrm{E}\right)+\mathrm{p}_{\mathrm{d}} \pi_{2}\left(\mathrm{E}_{2}-\mathrm{E}\right)\right]\right. \\
\left.+\lambda_{2}\left[\mathrm{p}_{\mathrm{u}} \pi_{3}\left(\mathrm{E}_{3}-\mathrm{E}\right)+\mathrm{p}_{\mathrm{d}} \pi_{4}\left(\mathrm{E}_{4}-\mathrm{E}\right)\right]\right\} \sigma / \sqrt{ } \tau \\
=\operatorname{Cov}\left(\mathrm{Y}_{\tau-1}, \mathrm{x}_{\tau}{ }^{\prime}\right)+2 \mathrm{~A} \sigma / \sqrt{ } \tau,
\end{gathered}
$$

where $A$ is a linear function of $\lambda_{1}$ and $\lambda_{2}$, of the type $\lambda_{1} \alpha+\lambda_{2} \beta$. We want to show that $2 A \sigma / \sqrt{ } \tau$ is $\mathrm{O}(1 / \sqrt{ } \tau)$ with the same degree of precision as in BV. By the Schwartz inequality we have $\operatorname{Cov}^{2}\left(Y_{\tau-1}, x_{\tau}\right) \leq \operatorname{Var} Y_{\tau-1} \operatorname{Varx}_{\tau}$. Since $\operatorname{VarY}_{\tau-1}=\sigma^{2}(1+2 \mathrm{k} V(\tau-1) / \sigma)+O(1 / \sqrt{ } \tau)+\mathrm{O}\left(\mathrm{k}^{2}\right)$ and $\operatorname{Varx}_{\tau}$ is at most equal to $\sigma^{2} \tau^{-1}\left[\mathrm{O}\left(\mathrm{k}^{2}\right)-\mathrm{f}\left(\lambda_{1}, \lambda_{2}\right)\right]$, we get from this inequality that $\operatorname{Cov}^{2}\left(\mathrm{Y}_{\tau-1}, \mathrm{x}_{\tau}\right)$ is less than or equal to $\left[\sigma^{4} \tau^{-1}+2 \mathrm{k} \sigma^{3} \sqrt{ }\left(1-\tau^{-1}\right) / \sqrt{ } \tau\right]\left[\mathrm{O}\left(\mathrm{k}^{2}\right)-\mathrm{f}\left(\lambda_{1}, \lambda_{2}\right)\right]$ plus terms of order higher than $1 / \tau$. All the terms in this last expression are at most $O(1 / \tau)$, given that $\operatorname{kf}\left(\lambda_{1}, \lambda_{2}\right)$ is at most $\mathrm{O}(1 / \sqrt{ } \tau)$ since $\mathrm{k} \lambda_{1}<\gamma \mathrm{k}=\mathrm{O}(1 / \sqrt{ } \tau)$. Hence, $\operatorname{Cov}\left(\mathrm{Y}_{\tau-1}, \mathrm{x}_{\tau}\right)$ is at most $\mathrm{O}(1 / \sqrt{ } \tau)$, QED.

The last step is to show that $\operatorname{Cov}\left(\mathrm{Y}_{\tau-1}, \mathrm{X}_{\tau}{ }^{\prime}\right)$ is $\mathrm{O}(1 / \sqrt{ } \tau)$, in which case (A7) implies that $2 \mathrm{~A} \sigma / \sqrt{ } \tau$ will also be $\mathrm{O}(1 / \sqrt{ } \tau)$. Replacing $\mathrm{Y}_{\tau-1}$ by the sum $\Sigma \mathrm{x}_{\mathrm{i}}$, we find that $\operatorname{Cov}\left(\mathrm{Y}_{\tau-1}, \mathrm{x}_{\tau}{ }^{\prime}\right)=$ $\Sigma \operatorname{Cov}\left(\mathrm{x}_{\tau-\mathrm{i}}, \mathrm{X}_{\tau}{ }^{\prime}\right)$. Evaluating the terms in the sum on the basis of the BV relation (A14) (p. 287) we find that, in that study's notation,

$$
\Sigma \operatorname{Cov}\left(\mathrm{x}_{\tau-\mathrm{i}}, \mathrm{x}_{\tau}{ }^{\prime}\right)=\Sigma \mathrm{p}_{\tau-\mathrm{i}}\left(1-\mathrm{p}_{\tau-\mathrm{i}}\right) \Theta^{\mathrm{i}} 2^{\mathrm{i}}(\operatorname{lnu}-\operatorname{lnd})^{2} \leq(1 / 4) \Sigma \Theta^{\mathrm{i}} 2^{\mathrm{i}}\left(4 \sigma^{2} / \tau\right)
$$


where we have used relation $(A 17)$ of $B V$. Since $\Sigma \Theta^{\mathrm{i}} 2^{\mathrm{i}}=\left[2 \Theta-(2 \Theta)^{\tau}\right] /[1-2 \Theta]$, we can neglect the factor $(2 \Theta)^{\tau}$, as in BV p. 290. Similarly, replacing $2 \Theta /[1-2 \Theta]$ into the RHS of (A8) by its asymptotic value $\sqrt{ } \tau[\mathrm{k} / 2 \sigma+\mathrm{O}(1 / \sqrt{ } \tau)]$ (from (A23) of BV), we find that $\operatorname{Cov}\left(\mathrm{Y}_{\tau-1}, \mathrm{x}_{\tau}{ }^{\prime}\right)$ is $\mathrm{O}(1 / \sqrt{ } \tau)$, QED.

This key result allows us now to employ the same technique as in BV in finding the asymptotic properties of the RHS of (A3). It implies that for large $\tau$ and small $\mathrm{k}$ the factor $\underline{\mathrm{x}}_{\tau}$ in expression (A3) can be neglected, implying that $\mathrm{C}_{\mathrm{ad}}$ can be approximated by expression (13). As argued in BV (p. 277) the distribution of $\mathrm{Y}$ for large $\tau$ tends to the normal with mean and variance given by (A4); hence, the distribution of $S_{\tau}$ tends to the corresponding lognormal distribution. Similarly, if the number of periods T- $\tau$ from ex-dividend date to option expiration is also large then the term $\mathrm{B}_{\tau \mathrm{a}}+\mathrm{N}_{\tau \mathrm{a}}(1-\gamma) \mathrm{S}_{0} \mathrm{e}^{\mathrm{Y}}$ would tend to a Black-Scholes call option value with variance $\sigma^{2}\left[1+(2 \mathrm{k} \sqrt{ } \mathrm{T}-\tau) /\left(\sigma \sqrt{ } \mathrm{t}-\mathrm{t}_{1}\right)\right]$. Theorem 2 now follows by using the standard $\mathrm{RGW}$ approach in order to evaluate the limiting form of (13).

\section{Proof of Theorem 3.}

The main task is to show that such a portfolio exists and is the optimal hedging portfolio at time $\tau-1$, since this would restore the convexity in $N_{j}$ of the constraints (5) for all $j \leq \tau-2$. The key to the proof is the form of the constraint (14a) when at least one of the points $u S_{\tau-1}$ and $d S_{\tau-1}$ lies within the indicated interval. There are many possibilities; only the most important or difficult to prove will be covered here. By Lemma $2 \mathrm{~N}_{\tau b} \in[-1,0]$, implying that the slopes of both constraints in (14a) are $-S_{\tau}(1+k)$ and $-(1+k) S_{\tau}+D k$ for $N_{\tau-1} \leq-1$, and $-(1-k) S_{\tau}$ and $-(1-k) S_{\tau}-D k$ for $\mathrm{N}_{\tau-1} \geq 0$. By (1) and (9) $\mathrm{N}_{\tau-1} *$, the optimal $\mathrm{N}_{\tau-1}$, will lie within the interval [-1,0] if it can be shown 
that it is the $\mathrm{u}$-and d-branches of the constraints at the RHS of (14a) that bind respectively at $\mathrm{N}_{\tau-1}$ $=-1$ and $\mathrm{N}_{\tau-1}=0$.

If $N_{\tau b}=-1$ then for $N_{\tau-1}=-1$ it is the relative sizes of $X$ and $X / R^{T-\tau}+D$ that will determine whether it is the first or the second term in braces in the RHS of (14a) that binds. It will be assumed that we are in the situation shown in Figure 1 , with $X /(1-k)<X / R^{T-\tau}+D$, which is the most complex; in such a case we have $-1<\mathrm{N}_{\tau b}(\mathrm{u})<\mathrm{N}_{\tau b}(\mathrm{~d}) \leq 0$ for $\mathrm{S}_{\tau}$ within the interval indicated in (14a). Consider first the case where the second terms in the RHS of (14a) bind at both $\mathrm{u}-$ and dbranches. For $\mathrm{N}_{\tau-1}=-1$ the $\mathrm{u}$-branch lies above the d-branch if $(1+\mathrm{k})(\mathrm{u}-\mathrm{d}) \mathrm{S}_{\tau-1}>$ $\Delta \mathrm{B}_{\tau \mathrm{b}}+(1+\mathrm{k}) \Delta \mathrm{N}_{\tau \mathrm{b}}\left(\mathrm{S}_{\tau}-\mathrm{D}\right)$, where $\Delta \mathrm{B}_{\tau \mathrm{b}} \equiv \mathrm{B}_{\tau \mathrm{b}}(\mathrm{d})-\mathrm{B}_{\tau \mathrm{b}}(\mathrm{u})$ and $\Delta \mathrm{N}_{\tau \mathrm{b}}\left(\mathrm{S}_{\tau^{-}} \mathrm{D}\right) \equiv \mathrm{N}_{\tau \mathrm{b}}(\mathrm{d})\left(\mathrm{d} \mathrm{S}_{\tau-1}-\mathrm{D}\right)-\mathrm{N}_{\tau \mathrm{b}}(\mathrm{u})\left(\mathrm{u} \mathrm{S}_{\tau-1^{-}}\right.$ D); this inequality holds by the convexities shown in Lemma 3. Similarly, at $\mathrm{N}_{\tau-1}=0 \Delta \mathrm{B}_{\tau \mathrm{b}}+(1-$ k) $\Delta \mathrm{N}_{\tau \mathrm{b}}\left(\mathrm{S}_{\tau}-\mathrm{D}\right)>0$ by Lemma 3 . The constraints in (14a) become then convex, implying by (1) and (9) that they have a unique intersection, which defines $\mathrm{N}_{\tau-1}{ }^{*}, \mathrm{QED}$.

Similarly, if it is the first term in (14a) that binds in both branches the d-branch is dominant for all $\mathrm{N}_{\tau-1} \in(-1,0)$ and the $\mathrm{u}$-branch for $\mathrm{N}_{\tau-1} \leq-1$, implying that $\mathrm{N}_{\tau-1}{ }^{*}=-1$. Note that, since the slope of the first term exceeds both slopes of the second term in (14a), we only need to compare the second terms in both branches if the second term in the $\mathrm{u}$-branch is $\leq X$ at $N_{\tau-1}=-1$.

For $\mathrm{D}=0$ it was already known from $\mathrm{BV}$ and BLPS that the optimal perfectly hedging portfolio is a replicating one given by (7b). This implies that for $\mathrm{D}=0$ the constraints in (14a) intersect as in Figure A2: the portfolio is defined by point $\tilde{N}$, where the flattest part of the $\mathrm{u}-$ branch intersects with the steepest part of the d-branch. This type of intersection is also preserved when D is $>0$ but (1) and (9) hold, as it can be easily shown by induction on T- $\tau$. This point is also the optimal portfolio $\left(\mathrm{N}_{\tau-1}{ }^{*}, \mathrm{~B}_{\tau-1}{ }^{*}\right)$ when it is not restricted by the immediate 
exercise constraint, as in Figure A2. In this case the lack of convexity of the constraints in the RHS of (14a) does not prevent the existence of a single replicating portfolio corresponding to deferred exercise and given by (15a,b).

By contrast, in the situation depicted in Figure A3 the portfolio at $\tilde{\mathrm{N}}$ is infeasible since it lies above the immediate exercise constraint for the u-branch. Hence, the optimal hedging portfolio corresponds to a portfolio replicating immediate exercise for an up move and deferred exercise for a down move. This portfolio is given by $(16 a, b)$. The optimality of the solutions of both $(15 a, b)$ and $(16 a, b)$ comes from an application of the program (4)-(6), in conjunction with inequalities (1) and (9) on the slopes of the constraints in Figures A2 and A3. Last, we have $\mathrm{N}_{\tau-1} *=-1, \mathrm{~B}_{\tau-1} *=\mathrm{X}$ when the immediate exercise constraint intersects the vertical axis below the point A in Figure A3.

It was thus shown that replication is optimal at $\tau-1$. It is also easy to show that the optimal portfolio $\left(\mathrm{N}_{\tau-1} * \mathrm{~B}_{\tau-1} *\right)$ along the successive nodes of the binomial tree satisfies the conditions for the optimality of replication of the BLPS Theorem 3, as with the long call. This completes the proof of the theorem.

Figure A2

Figure A3 


\section{$\underline{\text { References }}$}

Bensaïd, B., J. P. Lesne, H. Pagès, and J. Scheinkman, 1992, Derivative asset pricing with transaction costs, Mathematical Finance 2, 63-86.

Black, F., 1975, Fact and fantasy in the use of options, Financial Analysts Journal 31, 36-41, 61-72.

Black, F. and M. Scholes, 1973, The pricing of options and corporate liabilities, Journal of Political Economy 81, 637-659.

Boyle, P. P. and T. Vorst, 1992, Option replication in discrete time with transactions costs, Journal of Finance 47, 271-293.

Constantinides, G., 1986, Capital market equilibrium with transactions costs, Journal of Political Economy 94, 842-862.

Cox, J. C., S. Ross and M. Rubinstein, 1979, Option pricing: A simplified approach, Journal of Financial Economics 7, 229-263.

Cox, J. C. and M. Rubinstein, 1985, Options markets (Prentice Hall, Englewood Cliffs).

Davis, M. H. A., V. G. Panas, and T. Zariphopoulou, 1993, European option pricing with transaction costs, SIAM Journal of Control and Optimization 31, 470-493.

Dumas, B. and E. Luciano, 1991, An exact solution to a dynamic portfolio choice problem under transactions costs, Journal of Finance 46, 577-595.

Edirisinghe, C., Naik, V., and Uppal, R., 1993, Optimal replication of options with transaction costs and trading restrictions, Journal of Financial and Quantitative Analysis 28, 117-138.

Flesaker, B. and L. P. Hughston, 1994, Contingent claim replication in continuous time with transaction costs, Working paper (Merrill Lynch).

Geske, R., 1979, A note on an analytical formula for unprotected american call options on stocks with known dividends, Journal of Financial Economics 7, 375-380.

Henrotte, P., 1993, Transactions costs and duplication strategies, Working paper (Graduate School of Business, Stanford University).

Hodges, S. and A. Neuberger, 1989, Optimal replication of contingent claims under transactions costs, Review of Futures Markets 8, 222-242.

Hull, J. C., 1997, Options, futures, and other derivatives (Prentice-Hall, Englewood Cliffs).

Jarrow, R. and S. Turnbull, 1996, Derivative securities (Southwestern, Cincinnati).

Lefoll, J. and S. Perrakis, 1995, Transactions costs and option bid-and-ask spread on the Swiss Options and Financial Futures Exchange (SOFFEX), Canadian Journal of Administrative Sciences 12, 276-289. 
Leland, H., 1985, Option pricing and replication with transactions costs, Journal of Finance 40, 1283-1301.

Merton, R.C., 1973, Theory of rational option pricing, Bell Journal of Economics and Management Science 4, 141-183.

Merton, R.C., 1989, On the Application of the continuous-time theory of finance to financial intermediation and insurance, The Geneva Papers on Risk and Insurance 14, 225-261.

Omberg, E., 1987, A note on the convergence of binomial-pricing and compound-option models, Journal of Finance 42, 463-469.

Perrakis, S. and J. Lefoll, 1997a, Derivative asset pricing with transactions costs: An extension, Computational Economics 10, 359-376.

Perrakis, S. and J. Lefoll, 1997b, Option pricing and replication with transaction costs and dividends, Working paper 97.02 (International Finance Laboratory, Université de Genève).

Rendleman, R. and B. Bartler, 1979, Two-state option pricing, Journal of Finance 34, 1093-1110.

Roll, R., 1977, An analytic valuation formula for unprotected american call options on stocks with known dividends, Journal of Financial Economics 5, 251-258.

Selby, M. J. P. and S. D. Hodges, 1987, On the evaluation of compound options, Management Science 33, 347-355.

Soner, H. M., S. E. Shreve, and J. Cvitanic, 1995, There is no nontrivial hedging portfolio for option pricing with transaction costs, Annals of Applied Probability 5, 327-355.

Whaley, R. E., 1981, On the valuation of american call options on stocks with known dividends, Journal of Financial Economics 9, 207-212. 


\section{Endnotes}

1. In fact, the derived portfolios replicate exercise or deferral at the successor nodes. Nonetheless, the super-replication approach is necessary in American options since the optimality of replication is parameter-dependent, as we show in this paper. The difference between replication and super-replication in the analytical structure of the model is shown in the next section.

2. See BV for the ask, and PL for the bid.

3. It is assumed, following Roll (1977), that the dividend is paid with certainty at time $\tau$ no matter what the price of the stock; hence, for large values of $\mathrm{T}$ and $\tau$ and low values of $\mathrm{S}_{\tau}$ the dividend policy must be of the constant yield or less. Further, it is assumed without loss of generality that payment of the dividend does not alter the initial binomial process.

4. Our results can easily be extended without reformulation to the case where the ex-dividend price is $S_{\tau}-\delta D$, with $0<\delta 1$.

5. An additional requirement is that the terminal price must satisfy $S_{n} \notin[X /(1+k), X /(1-k)]$. As shown in PL, replication is still optimal when there is a value of $S_{n}$ in the interval [X/(1+k),X/(1-k)].

6. When the stock price is in the indicated interval, it is cheaper for an investor who wishes to own stock to exercise the option, even though the stock price may be below the exercised price. 
7. These properties were originally proven in Merton (1973). The properties of the replicating portfolios $\left(\mathrm{N}_{0 \mathrm{i}}, \mathrm{B}_{0 \mathrm{i}}\right), \mathrm{i}=\mathrm{a}, \mathrm{b}$, as functions of $\mathrm{S}_{0}$ are easily seen to hold; see, for instance, $\mathrm{BV}$.

8. Although this case is a theoretical possibility, it did not appear in any one of our simulation results. For the constant dividend yield case the second intersection point does not appear if the dividend yield exceeds the transaction cost parameter $k$, as is usually the case.

9. Note that this portfolio is independent of the holdings $\left(\mathrm{N}_{\tau-1}, \mathrm{~B}_{\tau-1}\right)$.

10. This point is important and controversial. The optimal policy at each node is dependent on the inherited amount of stock. If the two boundary values $\mathrm{N}_{\min }$ and $\mathrm{N}_{\max }$ were also dependent on that inherited amount the dynamic programming algorithm presented by BLPS would have become explosive very quickly, given the increase in the number of possible paths throughout the binomial tree. An incorrect statement to that effect was made in a paper by Edirisinghe et al (1993, p. 119). The proof for the independence is in the original BLPS paper, as two of its co-authors showed us in a private communication. We are indebted to Bernard Bensaïd and Jean-Philippe Lesne for pointing out to us this property of their algorithm.

11. Theorem 1 corresponds to Theorems 1 and 2 in our working paper (Perrakis and Lefoll, 1997b). Theorem 1 demonstrates that the stockholdings in the optimal portfolio lie between 0 and 1 , while Theorem 2 proves the replication result. Note that because of this Theorem 2 in this paper is Theorem 3 in the working paper, Theorem 3 is Theorem 4, etc. 
12. Otherwise (9) will be violated for low values of $S_{\tau-1}$. Our results are also valid for dividend policies with $D=\gamma S_{\tau}$ for all $S_{\tau}$ below a certain limit, and $D$ constant for higher $S_{\tau}$ 's.

13. See, for instance Cox and Rubinstein (1985), p. 240.

14. This limit is reached under an oscillating pattern that precludes the estimation of the number of subdivisions necessary to reach an accurate solution; see Omberg (1987). In practice, most textbooks suggest that as few as 30 subdivisions may be enough for an acceptable accuracy level in most applications. See Hull (1997, p. 348), and Jarrow and Turnbull (1996, p. 328).

15. The Roll-Geske-Whaley procedure normally assumes a constant dividend, whose discounted value is subtracted from the initial stock price $S_{0}$. While this is a reasonable formulation in the absence of transactions costs, it would lead to an underestimation of the magnitude of the costs of hedging the intermediary's position, since the value of the stock does not include the dividend.

16. Since the optimal policy turns out to be independent of the path of values of $S_{\tau}$ in Theorem 3 , we omit the argument $\omega_{\tau}$ hereafter. Recall also that relations (9) are automatically satisfied when (1) holds.

17. The value of $\sigma$ is the one used by $\mathrm{BV}$, while the value of $\mathrm{k}$ represents the maximum bid-ask spread for stock quotations found in the Swiss market by Lefoll and Perrakis (1995).

18. See PL. 
19. See the proof of Theorem 1 in our working paper (Perrakis and Lefoll, 1997b). Note that for a constant $\mathrm{k}$ and for such large values of $\tau$ relations (2) are expected to hold, and the bid price would become equal to the Merton bound as in Theorem 4, while the ask price would also become very large.

20. These are known as pseudo-American prices. They are computed under the assumption that exercise occurs either at ex-dividend date or at expiration for all nodes of the binomial tree.

21. The results were very similar when a constant $D=\$ 5$ was assumed.

22. The first function has slope $u\left(1-k^{2}\right)(R-d) /[R[u(1-k)-d(1+k)]]$, while the second's slope has the same denominator but a numerator equal to $\mathrm{u}\left[\mathrm{R}(1-\mathrm{k})^{2}-\mathrm{d}\left(1-\mathrm{k}^{2}\right)\right]$; both expressions satisfy the lemma, since they lie respectively in $(0,1+\mathrm{k})$ and $(0,1-\mathrm{k})$.

23. The proof is identical to the sequence followed in the BV derivation of their equations (7) and (8), where the starting stock price is $S_{\tau-2}$.

24. In this step, as well as in other parts of this proof, we make use of the fact that for any $\mathrm{q} \in(0, \mathrm{~m})$ we have $\mathrm{q}(\mathrm{m}-\mathrm{q}) \leq \mathrm{m}^{2} / 4 \leq 1 / 4$ if $\mathrm{m}<1$; here we have $\mathrm{q}=\mathrm{p}(1-2 \Theta)+\Theta$.

25. We assume, without loss of generality, that $\mathrm{O}\left(\mathrm{k}^{2}\right)$ tends to zero slower than $\mathrm{O}(\mathrm{k} / \mathrm{V} \tau)$. 


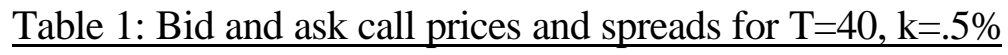

\begin{tabular}{|r|r|r|r|r|r||}
\hline \hline \multicolumn{1}{|c|}{$\mathrm{X}(\$)$} & \multicolumn{1}{|c|}{$\mathrm{C}_{\mathrm{ad}}(\$)$} & \multicolumn{1}{c|}{$\mathrm{C}_{\mathrm{bd}}(\$)$} & \multicolumn{1}{c|}{$\mathrm{C}_{\mathrm{aB}}(\$)$} & \multicolumn{1}{c|}{$\mathrm{C}_{\mathrm{bB}}(\$)$} & \multicolumn{1}{c|}{$\Delta \mathrm{C}_{\mathrm{d}}(\%)$} \\
\hline 85 & 16.270 & 16.056 & 16.128 & 13.336 & 1.33 \\
\hline 90 & 11.928 & 11.134 & 11.503 & 8.978 & 6.89 \\
\hline 95 & 8.295 & 6.493 & 7.679 & 5.350 & 24.37 \\
\hline 100 & 5.509 & 3.050 & 5.255 & 2.381 & 57.46 \\
\hline 105 & 3.517 & 1.265 & 3.444 & 0.558 & 94.21 \\
\hline 110 & 2.175 & 0.465 & 2.158 & 0.048 & 129.50 \\
\hline 115 & 1.296 & 0.150 & 1.294 & 0.004 & 158.63 \\
\hline
\end{tabular}




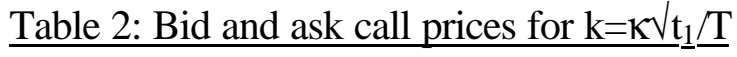

\begin{tabular}{||c|c|c||c|c||c|c||c|c||c||c||}
\hline \hline \multicolumn{3}{||c||}{$\mathrm{T}=6$} & \multicolumn{2}{c||}{$\mathrm{T}=20$} & \multicolumn{2}{c||}{$\mathrm{T}=50$} & \multicolumn{3}{c||}{$\mathrm{T}=100$} & \multicolumn{3}{|c|}{$\mathrm{T}=200$} \\
\hline $\mathrm{X}$ & $\mathrm{C}_{\mathrm{ad}}$ & $\mathrm{C}_{\mathrm{bd}}$ & $\mathrm{C}_{\mathrm{ad}}$ & $\mathrm{C}_{\mathrm{bd}}$ & $\mathrm{C}_{\mathrm{ad}}$ & $\mathrm{C}_{\mathrm{bd}+}$ & $\mathrm{C}_{\mathrm{ad}}$ & $\mathrm{C}_{\mathrm{bd}}$ & $\mathrm{C}_{\mathrm{ad}}$ & $\mathrm{C}_{\mathrm{bd}}$ \\
\hline 85 & 16.136 & 16.132 & 16.124 & 16.109 & 16.122 & 16.107 & 16.122 & 16.107 & 16.122 & 16.107 \\
\hline 90 & 11.457 & 11.408 & 11.501 & 11.447 & 11.502 & 11.448 & 11.501 & 11.449 & 11.499 & 11.446 \\
\hline 95 & 7.616 & 7.513 & 7.492 & 7.396 & 7.529 & 7.429 & 7.515 & 7.417 & 7.516 & 7.417 \\
\hline 100 & 4.588 & 4.494 & 4.517 & 4.400 & 4.529 & 4.409 & 4.522 & 4.398 & 4.519 & 4.394 \\
\hline 105 & 2.394 & 2.284 & 2.524 & 2.413 & 2.529 & 2.416 & 2.533 & 2.417 & 2.536 & 2.419 \\
\hline 110 & 1.283 & 0.573 & 1.320 & 1.231 & 1.338 & 1.246 & 1.343 & 1.251 & 1.346 & 1.253 \\
\hline 115 & 0.556 & 0.000 & 0.647 & 0.567 & 0.669 & 0.604 & 0.675 & 0.609 & 0.678 & 0.611 \\
\hline \hline
\end{tabular}


$\underline{\text { Table 3: Bid and ask call prices for } \mathrm{k}=0, \sigma=0.2 \sqrt{ } 1.05 \text { and } \sigma=0.2 \sqrt{ } .95}$

\begin{tabular}{|c|c|c|c|c|c|c|c|c|c|c|}
\hline \multicolumn{3}{|c|}{$\mathrm{T}=6$} & \multicolumn{2}{|c|}{$\mathrm{T}=20$} & \multicolumn{2}{|c|}{$\mathrm{T}=50$} & \multicolumn{2}{|c|}{$\mathrm{T}=100$} & \multicolumn{2}{|c|}{$\mathrm{T}=200$} \\
\hline$X$ & $\mathrm{C}_{\mathrm{ad}}$ & $\mathrm{C}_{\mathrm{bc}}$ & $\mathrm{C}_{\mathrm{ad}}$ & $\mathrm{C}_{\mathrm{bd}}$ & $\mathrm{C}_{\mathrm{ad}}$ & $\mathrm{C}_{\mathrm{bd}}$ & $\mathrm{C}_{\mathrm{ad}}$ & $\mathrm{C}_{\mathrm{bd}}$ & $\mathrm{C}_{\mathrm{ad}}$ & $\mathrm{C}_{\mathrm{bd}}$ \\
\hline 85 & 16.141 & 16.121 & 16.125 & 16.108 & 16.121 & 16.106 & 16.123 & 16.106 & 16.124 & 16.104 \\
\hline 90 & 11.454 & 11.408 & 11.501 & 11.447 & 11.504 & 11.446 & 11.506 & 11.444 & 11.504 & 11.433 \\
\hline 95 & 7.621 & 7.503 & 7.499 & 7.377 & 7.539 & 7.418 & 7.526 & 7.393 & 7.527 & 7.396 \\
\hline 100 & 4.603 & 4.461 & 4.529 & 4.381 & 4.545 & 4.389 & 4.538 & 4.379 & 4.535 & 4.375 \\
\hline 105 & 2.413 & 2.261 & 2.542 & 2.388 & 2.545 & 2.395 & 2.549 & 2.399 & 2.553 & 2.400 \\
\hline 110 & 1.301 & 0.541 & 1.339 & 1.207 & 1.353 & 1.227 & 1.359 & 1.234 & 1.361 & 1.236 \\
\hline 115 & 0.573 & 0.000 & 0.662 & 0.550 & 0.680 & 0.590 & 0.686 & 0.596 & 0.689 & 0.599 \\
\hline
\end{tabular}




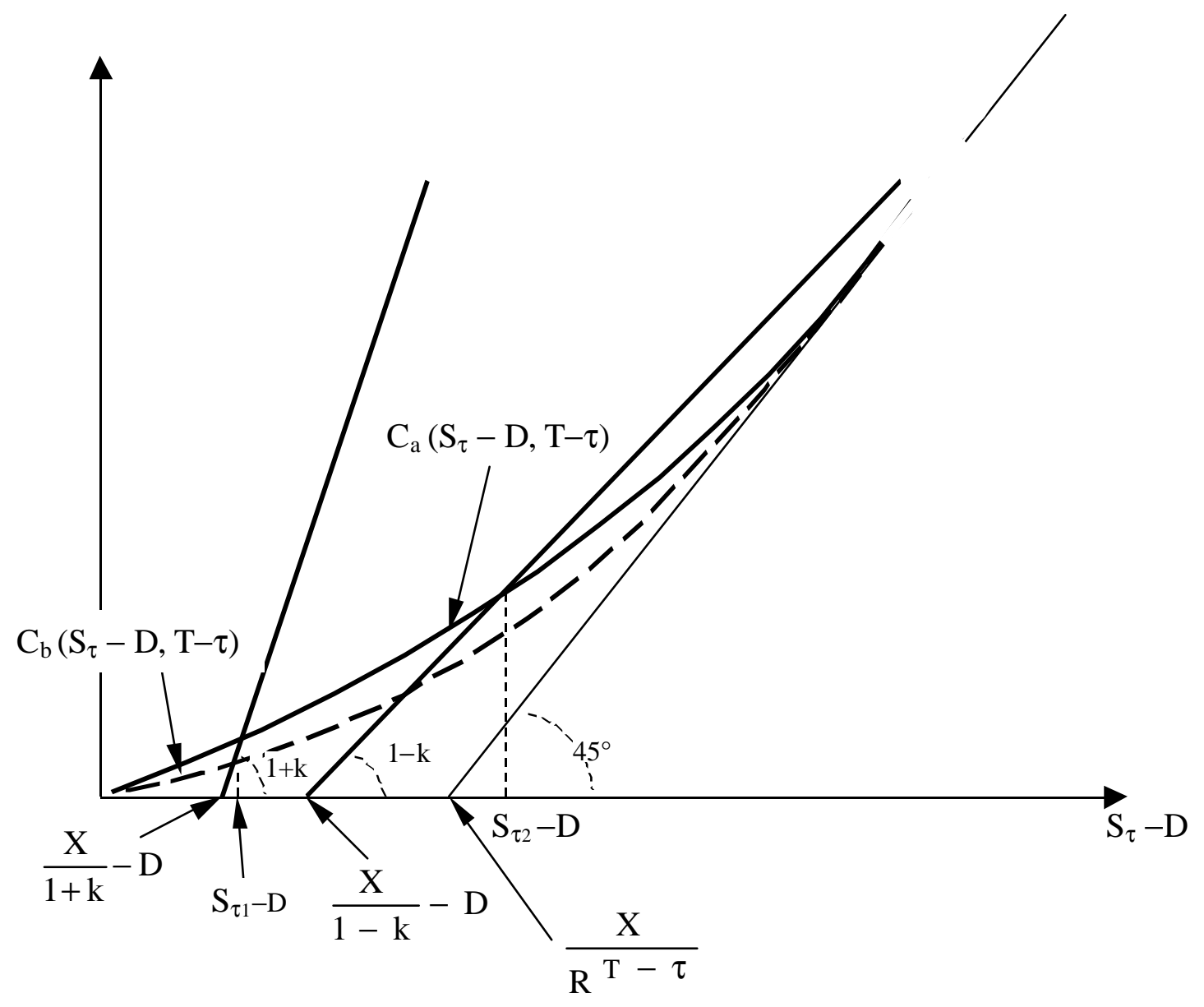

Figure 1 


$$
\begin{aligned}
& =\frac{\mathrm{X}}{1-\mathrm{k}}=106.380 \\
& \text { A } \\
& \mathrm{u}=1.05 \mathrm{k}=6 \% \\
& \mathrm{~d}=\mathrm{u}^{-1} \quad \mathrm{D}=5 \\
& \mathrm{R}=1 \\
& 100 \\
& 2 \\
& X=100 \\
& \text { B } \\
& \text { - }=\frac{X}{1+k}=94.34 \\
& \begin{array}{ll}
\mathrm{S}_{\mathrm{A}}=105 & \mathrm{~S}_{1}=110.25 \\
\mathrm{~S}_{\mathrm{B}}=95.238 & \mathrm{~S}_{2}=100 \\
& \mathrm{~S}_{3}=90.703
\end{array} \\
& \mathrm{C}_{\mathrm{a} 1}(105.25,1)=8.247 \\
& \mathrm{~N}_{\mathrm{a} 1}=0.748, \mathrm{~B}_{\mathrm{a} 1}=-70.477 \\
& \mathrm{C}_{\mathrm{a} 2}(95,1)=2.759 \\
& \mathrm{C}_{\mathrm{a} 3}(85.703,1)=0 \\
& \mathrm{~N}_{\mathrm{a} 2}=0.2772, \mathrm{~B}_{\mathrm{a} 2}=-23.577 \\
& \mathrm{~N}_{\mathrm{a} 3}=0, \mathrm{~B}_{\mathrm{a} 3}=0
\end{aligned}
$$

Figure 2 


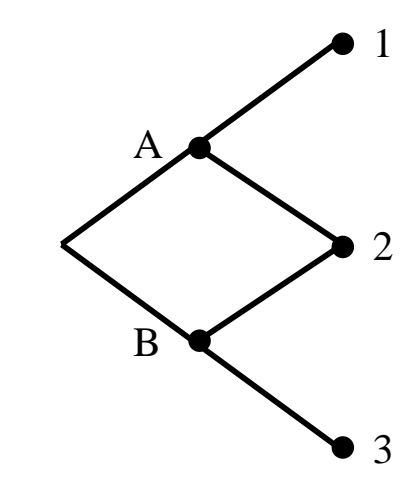

$\tau-2 \quad \tau-1 \quad \tau$

(a)

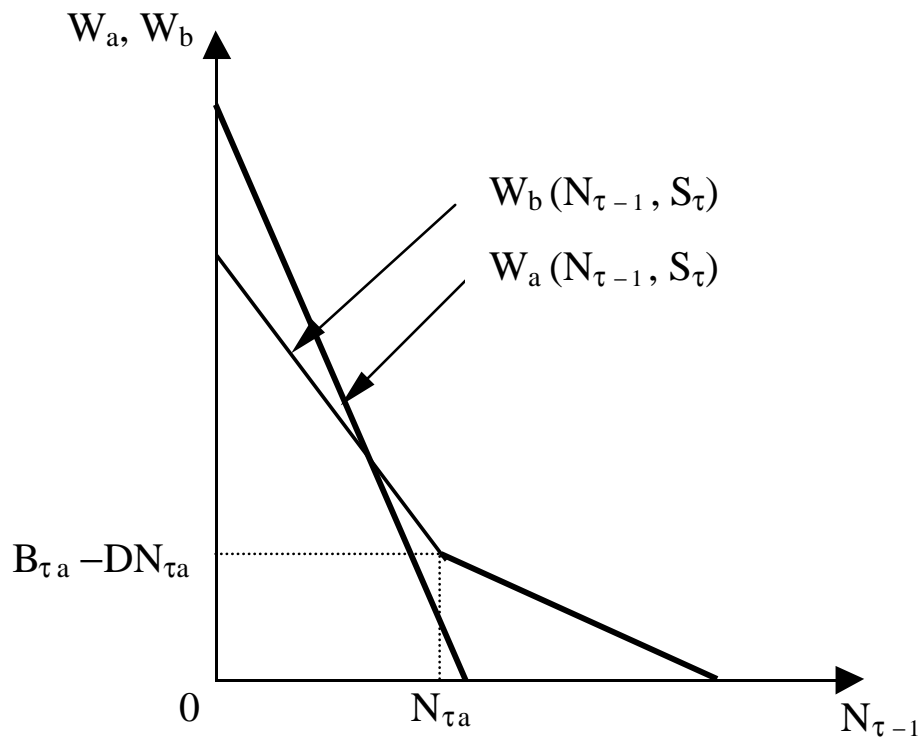

(c)

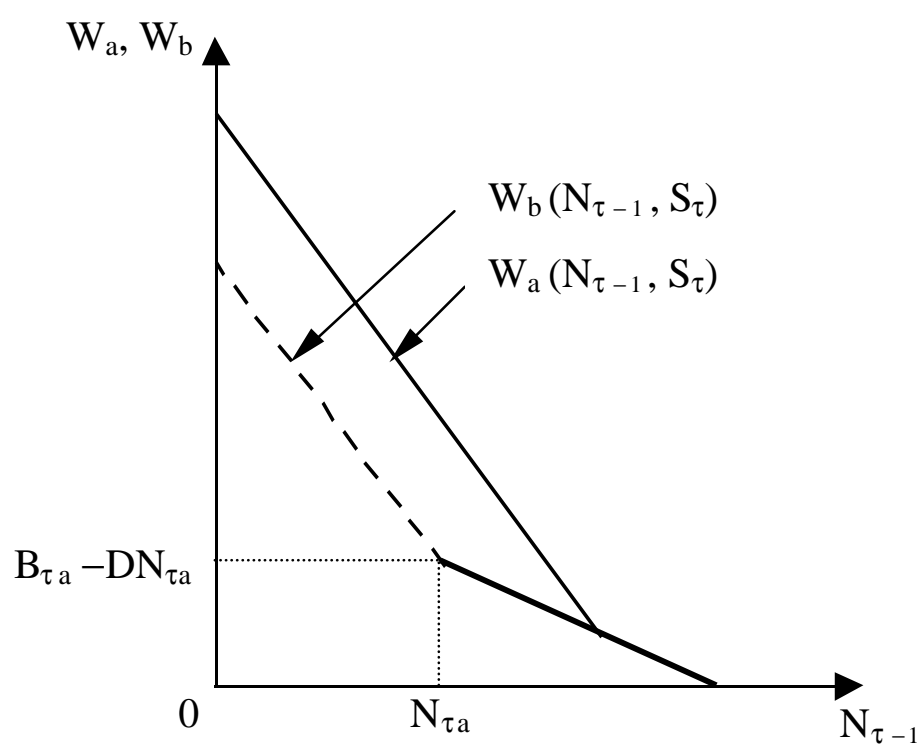

(b)

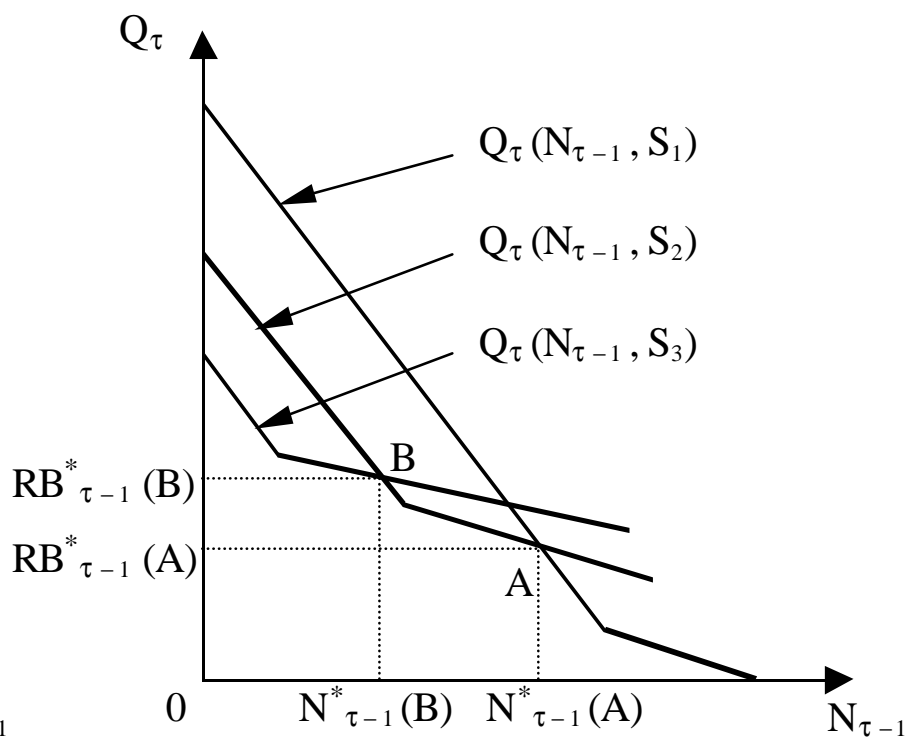

(d) 


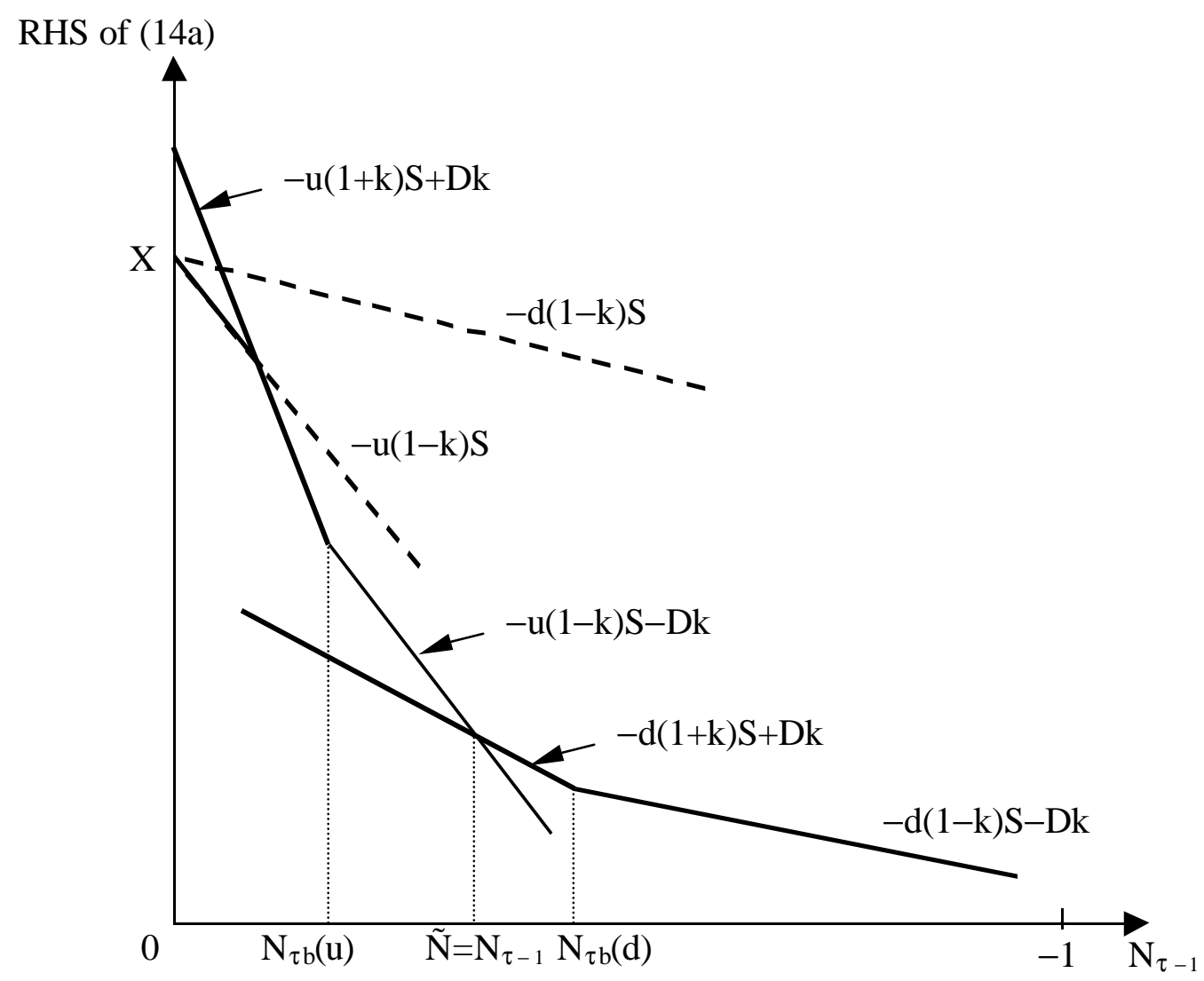

Note: Values indicate the slopes of the constraints.

Figure A2 


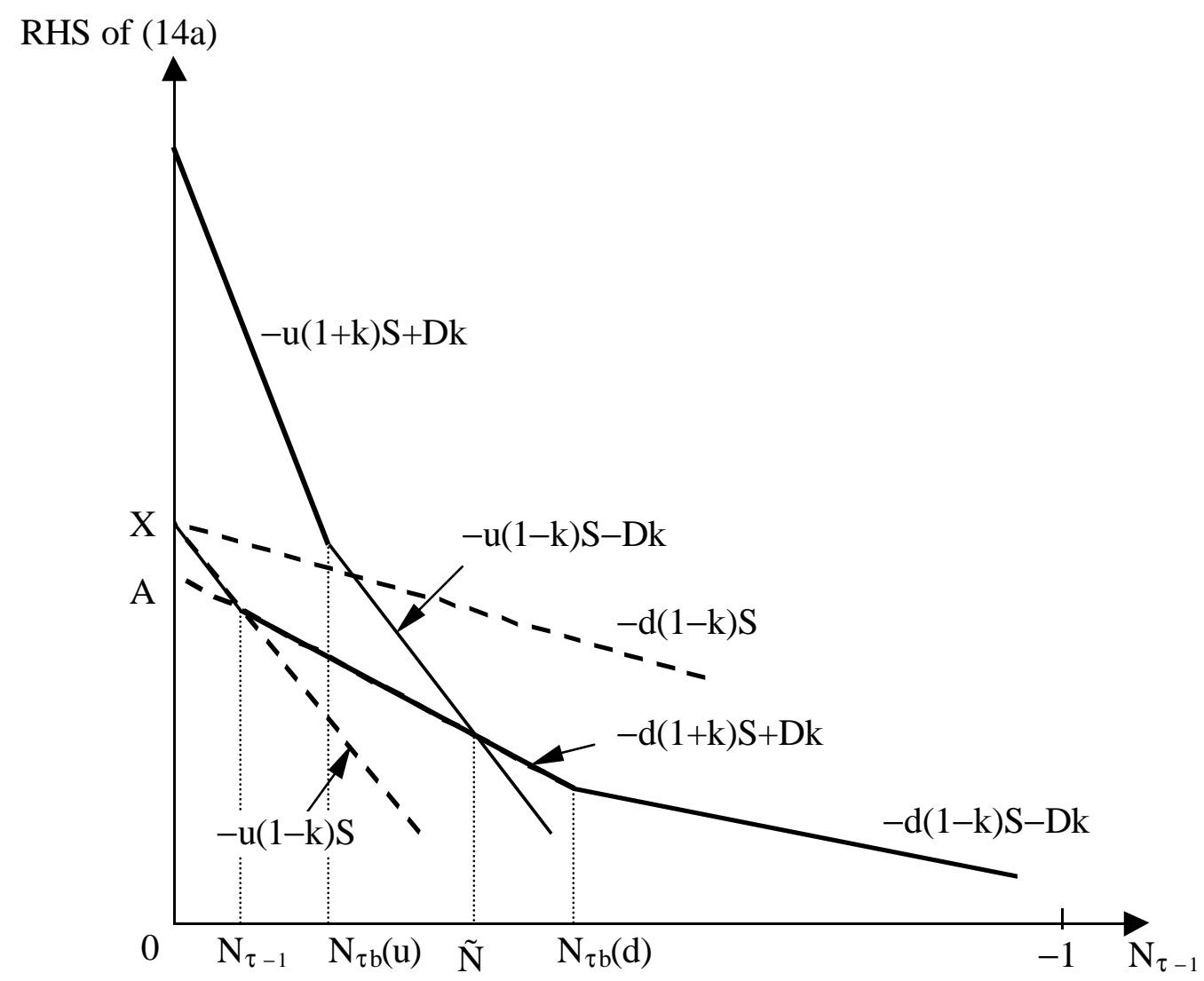

Note: Values indicate the slopes of the constraints.

\section{Figure A3}

